\title{
The impact of early life family structure on adult social attachment, alloparental behavior, and the neuropeptide systems regulating affiliative behaviors in the monogamous prairie vole (Microtus ochrogaster)
}

\author{
Todd H. Ahern ${ }^{\text {* }}$ and Larry J. Young ${ }^{1,2}$ \\ 1 Center for Behavioral Neuroscience and Yerkes National Primate Research Center, Emory University, Atlanta, GA, USA \\ ${ }^{2}$ Department of Psychiatry and Behavioral Sciences, Emory University School of Medicine, Atlanta, GA, USA
}

Edited by:

Anne Z. Murphy,

Georgia State University, USA

Reviewed by:

Karen Bales,

University of California, USA

Frances A. Champagne,

Columbia University, USA

\section{*Correspondence}

Todd H. Ahern, 954 Gatewood Rd. NE Yerkes National Primate Research Center, Emory University, Atlanta, GA 30322, USA.

e-mail: todd.h.ahern@gmail.com
Early social attachments lie at the heart of emotional and social development in many mammals, including humans. In nature, monogamous prairie voles (Microtus ochrogaster) experience considerable natural variation in early social attachment opportunities due to differences in family structure [e.g., single-mothers (SM), solitary breeding pairs, and communal groups]. We exploited some of this natural variation in family structure to examine the influence of early social environment on the development of adult social behavior. First, we characterized the parental care received by pups reared biparentally (BP) or by SM in the laboratory. Second, we examined whether BP-and SM-reared offspring differed in adult nurturing, bonding, and emotional behaviors. Finally, we investigated the effects of rearing condition on neuropeptide systems that regulate adult social behavior [oxytocin (OT), vasopressin, and corticotropin-releasing factor, (CRF)]. Observations revealed that SM-reared pups were exposed more frequently $(P<0.01)$, licked and groomed less $(P<0.01)$, and matured more slowly $(P<0.01)$ than BP-reared pups. In adulthood, there were striking socio-behavioral differences: SM-reared females showed low spontaneous, pup-directed alloparental behavior $(P<0.01)$ and both males and females from the SM-reared condition showed delayed partner preference formation. While rearing did not impact neuropeptide receptor densities in the ventral forebrain as we predicted, SM-reared animals, particularly females, had increased OT content $(P<0.01)$ and greater dorsal raphe CRF2 densities $(P<0.05)$ and both measures correlated with licking and grooming experienced during the first 10 days of life. These results suggest that naturalistic variation in social rearing conditions can introduce diversity into adult nurturing and attachment behaviors.

Keywords: early life experience, voles, social behavior, neuropeptide receptors, oxytocin, social attachment, monogamy

\section{INTRODUCTION}

Early life experience exerts a profound and persistent influence on a broad range of developmental trajectories, from emotional to physical. For example, in humans, abuse and neglect confer a vulnerability to depression, anxiety, alcoholism, obesity, and even heart disease, while parental warmth and affection can lead to resistance and resilience (for review, see Meaney, 2001). In rodents and non-human primates, variation in early care regulates adult stress reactivity, exploratory behavior, learning and memory, and sensitivity to drugs of abuse (Francis et al., 1999a; Liu et al., 2000; Levine, 2001; Meaney, 2001; Sanchez, 2006). Especially striking is the capacity of parenting to perpetuate particular behavioral profiles from one generation to the next, such as abuse behavior in macaques and licking and grooming (LG) behavior in rats (Francis et al., 1999a; Meaney, 2001; Sanchez, 2006). At the heart of this connection between early life and adult behavior lies early social attachment (Bowlby, 1973; Sable, 2004). Situated within the theoretical framework of attachment theory, the use of animal models is beginning to provide neurobiological insights into how early social environment can introduce and perpetuate individual variation in a variety of behavioral phenotypes (Meaney, 2001; Sable, 2004). In this study, we were particularly interested in how early life attachment factors guide expectations and behaviors in later social relationships.

Human rearing conditions are remarkably diverse. One of the most distinct factors producing variation in early life social experience is family structure and composition. Prairie voles (Microtus ochrogaster) provide an excellent opportunity to experimentally examine the effects of early life social experience on adult sociality. Prairie voles are small, genetically diverse, microtine rodents that adapt easily to laboratory environments and possess a rich repertoire of social behaviors (Carter et al., 1995; Young and Wang, 2004). Virgins of both sexes are highly social and exhibit spontaneous nurturing (or alloparental) care toward unrelated pups; adults form selective social attachments (or pair bonds) between mates; and breeding pairs usually display robust biparental (BP) care of offspring (Getz et al., 1981, 1993; Carter et al., 1995; Lonstein and DeVries, 2000; Young and Wang, 2004; Hammock and Young, 2005). 
In the wild, prairie voles maintain varied and often complex family structures. For most of the year, approximately one-third (37\%) of family units are single-mothers (SM), one-third (36\%) are male/ female breeder pairs, and one-third $(27 \%)$ are small communal groups consisting of a breeder pair and several reproductively inactive alloparents (Getz and Carter, 1996). Thus, variation in family structure offers a superb ethologically relevant model in which to examine how differences in early social environment influence the development of adult social nurturing and bonding behaviors.

Another advantage of using prairie voles is the large body of knowledge regarding the neurobiological mechanisms that regulate sociality. For example, oxytocin (OT) modulates spontaneous alloparental behavior and plays a central role in the formation of partner preferences (PP), the laboratory proxy of pair bonds, in female prairie voles (Williams et al., 1992; Insel and Hulihan, 1995; Olazábal and Young, 2006a). Arginine vasopressin (AVP), acting through the vasopressin 1 a receptor $(\mathrm{V} 1 \mathrm{aR})$, shows similar effects, predominately in males (Winslow et al., 1993; Wang et al., 1994). These two neuropeptide systems, as well as the corticotropin-releasing factor (CRF) and dopamine systems, have all been shown to play a role in complex prosocial behavior in prairie voles (DeVries et al., 2002; Aragona et al., 2003; Young and Wang, 2004; Lim et al., 2007).

Interestingly, prairie voles display remarkable individual variation in social behaviors, which have in some cases been linked to variation in neuropeptide systems. For example, in nature, approximately $40 \%$ of males adopt a wandering, rather than a pair-bonded, mating strategy (Getz and Carter, 1996). Variation in V1aR expression patterns has been associated with pair bonding in the laboratory and linked to reproductive success in naturalistic enclosures (Hammock and Young, 2005; Ophir et al., 2008a,b). In addition, female prairie voles display remarkable individual variation in spontaneous alloparental behavior toward pups. Approximately $50-70 \%$ of virgin females respond favorably to unrelated pups by displaying alloparental nurturing behavior, while the remainder either ignore or attack them (Lonstein and De Vries, 2000, 2001; Bales et al., 2004a; Olazábal and Young, 2005). Females that display alloparental behavior have higher densities of OT receptor (OTR) in the nucleus accumbens (NAcc), and blockade of those receptors inhibits alloparental behavior. The relative contribution of genetics and experience in producing this variation in social behavior is unknown.

The development of socially-relevant neuropeptide systems may be susceptible to early life experience. In rats, the amount of LG pups receive from their mothers can significantly affect the density of OTR and V1aR in brain regions that regulate stress and maternal responsiveness (Francis et al., 2000, 2002). Likewise, female victims of child-abuse present with lower concentrations of OT in their cerebrospinal fluid than non-abused counterparts (Heim et al., 2008).

In this study, we exploited some of the natural variation in prairie vole family structure to examine the influence of early life social experience on later-life social behavior. Specifically, we examined the developmental trajectories and adult social behavior of prairie voles raised in SM or BP rearing conditions. We then explored the neurobiological correlates of this behavioral variation. Our results suggest that early life rearing conditions can profoundly affect adult prosocial behavior and that these effects may be mediated by alterations in neuropeptide systems.

\section{MATERIALS AND METHODS EXPERIMENTAL ANIMALS}

All animals used in this study were bred in our laboratory at Emory University. Our colony is derived from field-caught stock originating from Illinois and is consistently outbred to maintain genetic diversity. Breeder pairs were housed in large ventilated breeder cages ( $34 \mathrm{~cm}$ long $\times 30 \mathrm{~cm}$ wide $\times 18 \mathrm{~cm}$ high) lined with bedding (bed-o-cob, Maumee, OH, USA) and a single nestlet. Pairs were maintained at $22^{\circ} \mathrm{C}$ on a $14: 10$ light-dark schedule with lights on at 06:00 $\mathrm{h}$ and had ad libitum access to food (LabDiet, rabbit chow) and water. Cages were changed weekly. At 18 days post-pairing, all males were handled and spot-shaved dorsally to distinguish male from female. Males that had been randomly assigned to the SM group were removed permanently to another room. Day 18 was used because earlier removals had been shown to influence in utero pup viability (McGuire et al., 1992). Males in the BP group were simply returned to the breeding home-cage after being handled and shaved. Pups were born between day 24 and day 28 post-pairing. Prairie vole litter sizes are variable (ranging from two to six), so litters were culled to provide approximately equal numbers of two, three, and four pup litters in each type of rearing condition. Pups were weaned at 21 days of age [postnatal day (PND) 22] and housed in same-sex, same-group pairs or trios. Same-group cage assignments were used to avoid having individuals from one particular group consistently be the smallest or least mature in a given cage.

All experimental offspring were derived from three strategically planned breeding cohorts (Table 1). Cohort 1 pups, which were derived from 18 family units $(B P=9, S M=9)$, were observed regularly during the neonatal period (PND1-15). Cohort 1 offspring remained behaviorally naïve until $\sim$ PND60 when they were sacrificed to obtain brains and blood plasma. Cohort 2 pups, which were derived from 24 family units $(\mathrm{BP}=12, \mathrm{SM}=12)$, remained undisturbed until adulthood when they underwent open-field, elevated plus maze (EPM), and naïve spontaneous alloparental behavior testing, with a week interval between each test (PND65 to PND90). Finally, cohort 3 pups, which were derived from another 24 family units $(\mathrm{BP}=12, \mathrm{SM}=12)$, remained behaviorally undisturbed until adulthood (PND90) when they were paired and tested for social attachment behavior in the PP test.

\section{FAMILY UNIT OBSERVATIONS}

We assessed the activities of all family units that gave birth in cohort $1(\mathrm{BP}=9, \mathrm{SM}=9)$. Observations began the day the first litter was born. Because there was variability in the due dates of the pups, observations were conducted from PND1 through 10 for all family units; three litters were eventually excluded because one BP litter and two SM litters were ignored and the pups did not survive beyond PND2. Fifteen family units $(\mathrm{BP}=8, \mathrm{SM}=7$ ) were thus observed for at least PND1-10. Twelve of these litters $(B P=6, S M=6)$ were further observed to PND15 to provide family data for the first 2 weeks of life. Each day, all family units were observed during three one-hour blocks: 06:00-07:00 h (begin lights ON), 12:30-13:30 h (lights ON), and 20:00-21:00 h (begin lights OFF; observations 
Table 1 | Assays by breeding cohort and age.

\begin{tabular}{|c|c|c|c|}
\hline & Neonatal period (PND1-15) & Weaning (PND22) & Adulthood (PND60-90) \\
\hline \multirow[t]{4}{*}{ Cohort 1} & Family observations & Weanling weights & Adult weights (PND60) \\
\hline & Pup weights & & Blood plasma corticosterone \\
\hline & & & OT in situ hybridization \\
\hline & & & OTR, V1aR, CRF1, CRF2 binding \\
\hline \multirow{3}{*}{ Cohort 2} & & & Elevated plus maze \\
\hline & & & Alloparental behavior test \\
\hline & & & Adult weights (PND90) \\
\hline \multirow[t]{2}{*}{ Cohort 3} & Pup weights & Weanling weights & Adult weights (PND90) \\
\hline & & & Mating \\
\hline
\end{tabular}

under $15 \mathrm{~W}$ red-light) based on a procedure previously established in our laboratory (Hammock and Young, 2005).

During each observation block, each family unit was spotchecked 10 times, with a 5-6 min interval between spot-checks. During each observation, the activities of the mother, the father (if present), and the pups were logged. The log was divided into three categories: nest occupancy (male, female, pups), activity (male, female, pups), type of nursing. For occupancy, each animal was either $\mathrm{ON}$ or OFF the nest. For activity, a range of behaviors was scored: LG, resting, nest building, wandering (walking or running), digging, eating, drinking, grooming self, grooming mate, and climbing/ jumping. Nursing postures included active (arch-backed or standing crouch) and passive (side). Behaviors within categories were mutually exclusive (e.g., the female could only be ON or OFF the nest), but data across categories were complementary (e.g., female ON nest, LG, and active nursing). For each category and behavior, data were simplified to 1 and $0 \mathrm{~s}$ within each spot-check to allow frequency and cumulative occurrence calculations across all 300480 spot-checks for each family unit (10 spot-checks $\times$ observation blocks $\times 10-15$ PNDs). Our a priori objectives were to examine LG, pup exposure, and when pups first ventured off the nest, but other factors (e.g., cumulative nursing) were considered.

Two separate types of analysis were conducted. After ruling out time-of-day effects, first we calculated the average frequency of each behavior over PND2-10 for each type of family unit. A simple Student's $t$-test was used for statistical comparison. Next, we accumulated the total number of occurrences of each behavior within each family unit over the first 15 PNDs and averaged across rearing condition. Pair-wise comparisons at PNDs 2, 5, 10, and 15 were performed, after testing for normality (Kolmogorov-Smirnov and Shapiro-Wilk tests) and for homogeneity of variance (Levene's test). $P<0.05$ was considered statistically significant.

\section{OFFSPRING WEIGHTS}

All pups were weighed on the day of birth (PND1), then weekly until weaning at PND22. Pups were gently removed from the nipples and placed in a plastic weigh container mounted on a scale sensitive to $0.01 \mathrm{~g}$. Animals were again weighed in adulthood
(PND60 for cohort $1+2$; PND90 for cohort $2+3$ ), using the same scale.

A $2(\operatorname{sex}) \times 2$ (group) $\times 2($ PND) ANOVA was used to analyze mass at weaning and in adulthood, with PND as a repeated measure. Post hoc pair-wise comparisons within each time point were used to examine group differences. $P<0.05$ was considered statistically significant.

\section{ADULT OFFSPRING BRAIN AND BLOOD ANALYSIS}

At $\sim 60$ days of age, a total of 36 cohort 1 animals ( $n=6$ males +6 females/rearing group; only one male and/or one female per litter) were anesthetized with vaporized isoflurane and rapidly decapitated. Approximately $200 \mu \mathrm{L}$ of trunk blood were collected in $1.5 \mathrm{~mL}$ EDTA-coated tubes (Brinkman Instruments Inc., 022379224) treated with $10 \mu \mathrm{L}$ of aprotinin (Trysol; Fisher Scientific: BP250310). Brains were then rapidly removed from the skull and snap frozen in powdered dry-ice. Brains were stored at $-80^{\circ} \mathrm{C}$ until sectioned. Trunk blood was maintained on ice, centrifuged ( $4000 \mathrm{rpm}, 4^{\circ} \mathrm{C}, 5 \mathrm{~min}$ ), and plasma was aliquoted $(10 \mu \mathrm{L})$ and stored at $-20^{\circ} \mathrm{C}$ for corticosterone assays (Bosch et al., 2009). All brains were cryostat sectioned from the olfactory bulbs through the locus coeruleus in a 1:6 series at $20 \mu \mathrm{M}$, thaw-mounted on super-frost plus slides (Fisher Scientific, 12-550-15), and maintained at $-80^{\circ} \mathrm{C}$ until assayed. Each of the six series was treated for one of the following: ${ }^{125} \mathrm{I}$ autoradiographic binding for V1aR, OTR, corticotropin-releasing factor receptor 1 (CRF1), and CRF2, as well as in situ hybridization for OT.

\section{Plasma corticosterone}

A commercially available radioimmunoassay kit was used to quantify plasma corticosterone concentrations (MP Biomedicals, Irvine, CA, USA). The kit has been validated previously for prairie voles (Taymans et al., 1997; Grippo et al., 2007). Prairie voles are glucocorticoid resistant leading to high basal concentrations of corticosterone, so aliquots were diluted 1:1000, instead of the standard 1:200, to give results within the linear portion of the standard curve. The lowest detectable dose was $7.7 \mathrm{ng} / \mathrm{mL}$, and the inter-assay variation coefficient was less than $7 \%$. Cross-reactivity with other steroids was less than $1 \%$. Values are given in $\mathrm{ng} / \mathrm{mL}$. 


\section{In situ hybridization}

In situ hybridization for OT was performed using a well-established protocol in our laboratory (Wang et al., 2000; Patisaul et al., 2003). OT mRNA was probed using a single, 41-base, ${ }^{35} \mathrm{~S}$-labeled oligonucleotide probe (GGG CTC AGC GCT CGG AGA AGG CAG ACT CAG GGT CGC AGG CG) complementary to nucleotides 906946 of the rat OT mRNA (GenBank Accession Number K01701). Following in situ hybridization, slices were rinsed, washed, and dried according to the protocol and exposed to Kodak BioMax MR film (Eastman Kodak Co., NY, USA) for 3 h. After confirming OT mRNA detection using film, slides were dipped in photographic emulsion (Kodak NTB-2), exposed for $3.5 \mathrm{~h}$, and then developed.

\section{In situ quantification and analysis}

Quantification of in situ hybridization OT mRNA silver grains in the paraventricular nucleus (PVN) was performed using AIS 6.0 (MCID, Canada) after digitization (MTI CCD72 camera). Both the number of OT-labeled clusters and the level of OT expression per neuron were estimated as follows. Under dark-field conditions, a $4 \times$ objective was used to identify and count silver-grain clusters (Young et al., 1994) throughout five adjacent sections of the PVN of the hypothalamus. Since adjacent sections were $120 \mu \mathrm{M}$ apart, it is not possible that the same neuron could appear in adjacent sections. Grain clusters in all five sections from both left and right hemispheres were summed to represent OT cell count and used for analysis.

In situ slides were then nuclear-stained using cresyl violet, coverslipped, and examined under bright-field conditions, using a $40 \times$ objective. The number of grains in approximately 20 clusters situated above large (and therefore neuron) nuclei were counted using a 50 pixel diameter circular cursor (Bosch et al., 2009). Bilateral grain counts from five adjacent sections were quantified and averaged, and background readings from the lateral hypothalamus were subtracted before statistical analysis.

Both number of clusters and number of grains/cluster were analyzed using two separate two-way ANOVAs. Post hoc pair-wise comparisons followed significant effects. $P<0.05$ was considered statistically significant.

\section{Receptor autoradiography}

Autoradiography for V1aR, OTR, CRF1, and CRF2 each followed similar procedures and have been previously published (Phelps and Young, 2003; Lim et al., 2005; Olazábal and Young, 2006a). Briefly, slides were thawed at room temperature until dry, then fixed in $0.1 \%$ paraformaldehyde-PBS ( $\mathrm{pH} 7.4$ ) for $2 \mathrm{~min}$, washed twice in $50 \mathrm{mM}$ Tris base $(\mathrm{pH}$ 7.4) for $10 \mathrm{~min}$ each. Slides were then incubated in tracer buffer ( $\mathrm{pH} 7.4)$ for either $1 \mathrm{~h}(\mathrm{~V} 1 \mathrm{aR}$ and OTR) or $2 \mathrm{~h}$ (CRF1 or CRF2). The tracer consisted of $50 \mathrm{mM}$ Tris base, $10 \mathrm{mM} \mathrm{MgCl}, 0.1 \%$ bovine serum albumin, plus one of the following radioligands: for $\mathrm{V} 1 \mathrm{aR}, 0.05 \mathrm{nM}^{125} \mathrm{I}-\mathrm{d}\left(\mathrm{CH}_{2}\right)_{5}(\mathrm{Tyr}[\mathrm{Me}])$ AVP (PerkinElmer); for OTR, $0.05 \mathrm{nM}{ }^{125} \mathrm{I}-\mathrm{d}\left(\mathrm{CH}_{2}\right)_{5}\left[\mathrm{Tyr}(\mathrm{Me})_{2}-\right.$ Tyr-NH $]_{9}$-OVT (PerkinElmer); for CRF1 and CRF2 $0.2 \mathrm{nM}$ ${ }^{125}$ I-sauvagine (PerkinElmer). ${ }^{125}$ I-sauvagine binds to both CRF1 and CRF2 with high affinity (Primus et al., 1997; Lim et al., 2005). To achieve CRF1 and CRF2 selective binding, a cold antagonist was also added to the tracer: $500 \mathrm{nM}$ CP-154,526, a selective CRF1 antagonist (a generous gift from Michael J. Owens, Emory
University), was used to reveal CRF2 binding; 500 nM Astressin-2B, a selective CRF2 antagonist (Sigma-Aldrich, A5227), was used to reveal CRF1 binding. These antagonists show selective binding properties in prairie voles (Lim et al., 2005; Bosch et al., 2009). Regardless of the tracer cocktail, slides were then washed in $50 \mathrm{mM}$ Tris base plus $10 \mathrm{mM} \mathrm{MgCl}(\mathrm{pH} 7.4) 4 \times 5 \mathrm{~min}$, plus $30 \mathrm{~min}$ with slow stirring on a magnetic stir plate. Finally, slides were dipped briefly in deionized water, dried under a stream of cool air, and apposed to Kodak MR film for $72 \mathrm{~h}$ (OTR and V1aR) or $85 \mathrm{~h}$ (CRF1 and CRF2). ${ }^{125} \mathrm{I}$-microscale standards (Amersham Biosciences/GE Healthcare) were applied to each film.

\section{Receptor autoradioagraphy quantification and analysis}

Quantification of autoradiograms followed previously published procedures (Phelps and Young, 2003; Lim et al., 2005). Films and microscale standards were digitized (MTI CCD72 camera) and quantified using AIS 6.0 (MCID, Canada). Once digitized, optical density measurements were taken bilaterally and averaged for each brain region across two to seven sections, based on the size of the region of interest. Optical density was converted automatically to decompositions per minute per milligram tissue (DPM) based on the microscale standards from each film. To control for non-specific background binding, DPM values from the corpus callosum were subtracted from the raw value for each region prior to statistical analysis, a procedure that has been used previously (Hammock and Young, 2005).

Due to the large number of brain regions that express each of the four neuropeptide receptor types, we analyzed the autoradiographic data in two tiers. Based on previous studies in prairie vole social behavior, our a priori objective was to test the hypothesis that early social experience could alter neuropeptide receptor expression in the ventral forebrain: in particular, OTR and CRF1 in the nucleus accumbens shell (NAcc-Shell), CRF2 in the NAcc septal pole, and V1aR in the ventral pallidum. Manipulations of all of these receptor populations have been shown to alter adult social behavior (Young and Wang, 2004; Lim et al., 2007). Therefore, in the first tier analysis, we conducted a 2 (group) $\times 2($ sex $) \times 4$ (receptor-type/specific-region) multiple ANOVA (MANOVA) to examine the effect of rearing condition on neuropeptide receptor expression in the ventral striatum.

The ventral forebrain is not the only area that regulates social and emotional behaviors, nor is it the region most often associated with early life experience, since rats and mice express negligible levels of receptors there. In our second tier analysis, we chose four to five other brain regions for each receptor type based on their role in social and emotional behaviors and/or their sensitivity to early experience, and conducted a separate 2 (group) $\times 2$ (sex) MANOVA for each one. Post hoc tests followed significant effects. Again, a $P<0.05$ was considered statistically significant. To reiterate, all neuropeptide system analyses above were performed using adult, behaviorally naïve, brains obtained from cohort 1 adult offspring, for which we had early life experience data.

\section{ADULT OFFSPRING BEHAVIOR Open-field}

To examine adult emotional and spontaneous nurturing behavior, cohort 2 animals were bred in the same manner as cohort 1 . 
At $\sim 60$ days of age, all cohort 2 (Table 1) offspring were moved to a behavior room, allowed to acclimate at least one hour, and then underwent open-field testing (males $\mathrm{BP}=10, \mathrm{SM}=12$; females $\mathrm{BP}=12, \mathrm{SM}=10$; one male and/or one female per litter). Between 09:00-11:00 h, rounds of four animals (two males + two females) were run simultaneously for $20 \mathrm{~min}$ in $40 \mathrm{~cm} \times 40 \mathrm{~cm} \times 40 \mathrm{~cm}$ Plexiglas boxes separated by opaque white material and videorecorded from above; boxes were designated for male or female use only. Between each round, the open-field boxes were cleaned with a mild detergent (Alconox), wiped dry, cleaned with deionized water, and wiped dry again. The video-recordings were analyzed post hoc via an automated video-tracking program, EthoVision 3.0 (Noldus Information Technology, the Netherlands). Using features within the program, each open-field chamber was divided into the perimeter $($ wall $+10 \mathrm{~cm})$ and the center $(20 \mathrm{~cm} \times 20 \mathrm{~cm})-$ matching taped outlines applied to the underside of the boxes themselves. Behavior was processed in four consecutive $5 \mathrm{~min}$ time intervals. The first and last 5 min intervals were analyzed: the first represented responses to novelty and has been shown to be sensitive to early life experience (Meaney, 2001), while the last interval represented general activity. Behavioral measures included frequency (counts) in center, total time in center, and distance moved in the entire arena. The experimenter was blind to rearing condition. Each measure was divided by group and sex and tested for normality (Kolmogorov-Smirnov and Shapiro-Wilk tests) and for homogeneity of variance (Levene's test). Due to non-normality, all data from all groups and sexes were square-root transformed, tested for normality and homogeneity again, and then analyzed using a 2 (group) $\times 2($ sex $) \times 2$ (interval) repeated measures ANOVA, with interval as the repeated measure. Each test was followed by appropriate post hoc tests and pair-wise comparisons.

\section{Elevated plus maze}

Approximately 1 week after open-field testing, the same cohort 2 animals were moved to a behavior room (males $\mathrm{BP}=10, \mathrm{SM}=12$; females $\mathrm{BP}=12, \mathrm{SM}=10$; again, only one male and/or one female from each litter), allowed to acclimate at least 1 hour, and then underwent EPM testing between 09:00 and 11:00 h. The apparatus, which was raised $80 \mathrm{~cm}$ above the floor, measured $6 \mathrm{~cm} \times 6 \mathrm{~cm}$ at the center platform, and the center had two open arms $(50 \mathrm{~cm} \times 6 \mathrm{~cm} \times 0.6 \mathrm{~cm})$ and two closed arms $(50 \mathrm{~cm} \times 6 \mathrm{~cm} \times 15.5 \mathrm{~cm})$ extending from it. Each animal was placed in the center and allowed to roam for $5 \mathrm{~min}$. Behavior was video-recorded from above. As with the open-field, behaviors were analyzed by EthoVision 3.0. Raw measures included frequency (counts) and total time in each type of arm, and total distance moved in the entire arena. Behavioral parameters relevant to anxiety and exploration were then calculated: percent entries into the open arms [open arms count/(open arms count + closed arms count)], percent time in open arms [time in open arms/(time in open arms + time in closed arms)], and total distance moved. The EPM is often used as an anxiety assay in rodents and has also been used in prairie voles (Pitkow et al., 2001; Olazábal and Young, 2005; Stowe et al., 2005). Each measure was divided by group and sex and tested for normality (Kolmogorov-Smirnov and ShapiroWilk tests) and for homogeneity of variance (Levene's test). Due to non-normality, all data from all groups and sexes were square-root transformed, tested again for normality and homogeneity, and then analyzed using a 2 (group) $\times 2$ (sex) ANOVA. Each test was followed by appropriate post hoc tests and pair-wise comparisons on the transformed data. Two animals $(\mathrm{BP}=1$ male, $\mathrm{SM}=1$ male $)$ were excluded from the analysis because they fell from the apparatus.

\section{Naïve spontaneous aloparental behavior}

Approximately 1 week post-EPM testing, the same cohort 2 animals were moved to a behavior room, allowed to acclimate for at least one hour, and then examined for naïve spontaneous alloparental behavior between 0900 and $1100 \mathrm{~h}$. Prior to testing, each animal was moved to a large polycarbonate cage $(19 \mathrm{~cm} \times 45 \mathrm{~cm} \times 30 \mathrm{~cm})$ lined with bedding (bed-o-cob) and allowed to acclimate for approximately $25 \mathrm{~min}$. After acclimation, testing began when two pups (2-5 days of age) were placed in the cage opposite of the test animal. Animals were then observed by a trained experimenter blind to rearing condition and performance on previous tests. The following behavior categories were rated with the assistance of Stopwatch+ (available to download ${ }^{1}$ ): latency to approach pups, number of animals that attacked pups, time immobile over at least one pup, time LG at least one pup, and time away from pups (not in contact). A detailed posture analysis was not performed. If the test animal did attack the pups, the test was stopped immediately and pups were returned to their mother. While both males and females show spontaneous alloparental behavior, we were not concerned with a direct comparison of sex differences within rearing groups. After excluding animals that attacked pups, the spontaneous alloparental behavior data was split by sex (males $\mathrm{BP}=8, \mathrm{SM}=11$; females $\mathrm{BP}=7, \mathrm{SM}=9$ ) and then each behavior was analyzed using a 2 (group) Independent samples Kruskal-Wallis H, Monte Carlo exact non-parametric test, due to the extreme non-normality of the data. Finally, all animals were categorized as either parental or non-parental based on previously established criteria: $>5$ s LG and $>30$ s huddling or crouching over at least one of the pups (Lonstein and De Vries, 1999; Olazábal and Young, 2005). Chi-squared tests compared the proportion of parental animals across groups, within each sex.

\section{Partner preference testing}

Pup exposure has been shown to alter PP testing performance, so we generated another set of SM- and BP-reared in animals for cohort 3. To examine the formation of PP, 90 days old cohort 3 BP- and SMreared animals were paired at $08: 00 \mathrm{~h}$ with naïve colony animals of the opposite sex in a clean cage with ad libitum access to food and water and allowed to cohabitate for $24 \mathrm{~h}(N=12 / \mathrm{sex} /$ group; one male and/or one female per litter). The females were unprimed and therefore not immediately sexually receptive. The next morning at 08:00 h, all cohabitated animals were moved to a behavior testing room. Females were examined vaginally to determine if mating had likely occurred by rating the presence or absence of vaginal redness and the presence or absence of vaginal opening. Only animals that had both vaginal redness and vaginal opening were considered to have possibly mated. This method has been highly correlated with actual matings as observed by video-recording. All test animals then underwent a 3-h PP test. Briefly, the PP test consists of a socially "neutral" chamber flanked by two stimulus chambers (Williams et al.,

${ }^{1}$ http://www.cbn-atl.org/research/stopwatch.shtml 
1992; Winslow et al., 1993; Young and Wang, 2004). The "partner" animal is tethered in one stimulus chamber, while a "stranger" animal of similar sociosexual valence is tethered in the other. The strangers underwent the same cohabitation and testing regimen as the test and partner animals. The experimental animal is placed in the center, neutral chamber and is allowed to roam freely for $3 \mathrm{~h}$. Following the $3-\mathrm{h}$ test, all animals were returned to their cohabitation cages and allowed to cohabitate for 24 more hours (a total 48 cohabitation hours) and tested again in the same manner; the "partner" remained the same, but the "stranger" was new. Animals were again returned to their cohabitation cage after testing and remained together for another 5 days (a total of 1 week of cohabitation) and then tested again - for a total of three PP tests per experimental animal. Regardless of time point, all tests were video-recorded and analyzed post hoc for time spent huddling and number of center cage-crossings by an automated software system (SocialScan 2.0, Clever Sys Inc., Reston, VA, USA). Automated scoring for huddling with SocialScan has been validated for use with the PP test and demonstrates a remarkably high correlation with manual scoring $(R>0.99$; Ahern et al., 2009).

\section{RESULTS}

\section{FAMILY UNIT OBSERVATIONS}

Time alone on nest

Pups were considered exposed on the nest when neither the mother nor the father was on the nest during a spot-check. Data were analyzed using two complementary methods. First, we examined the frequency of spot-checks when pups were exposed. Because there were no time-of-day effects, all 30 spot-checks (10 from each observation block) were used to calculate a daily frequency. Daily frequencies from PND2-10 were then averaged and a simple Student's $t$-test was performed. SM-reared offspring experienced a greater frequency of time alone on the nest during PND2-10 than BP-reared pups $(P<0.001$; Figure 1A; $\mathrm{BP}=8$, $\mathrm{SM}=7)$.

We then examined the cumulative effect of these frequency differences. A total of twelve family units $(\mathrm{BP}=6, \mathrm{SM}=6)$ were fully observed from PND1-15. A 2 (family unit) $\times 4$ (PND) ANOVA, with PND as a repeated measure, revealed a main effect of $\operatorname{PND}\left(F_{1,10}=38.438, P<0.001\right)$, rearing condition $\left(F_{1,10}=24.720\right.$,

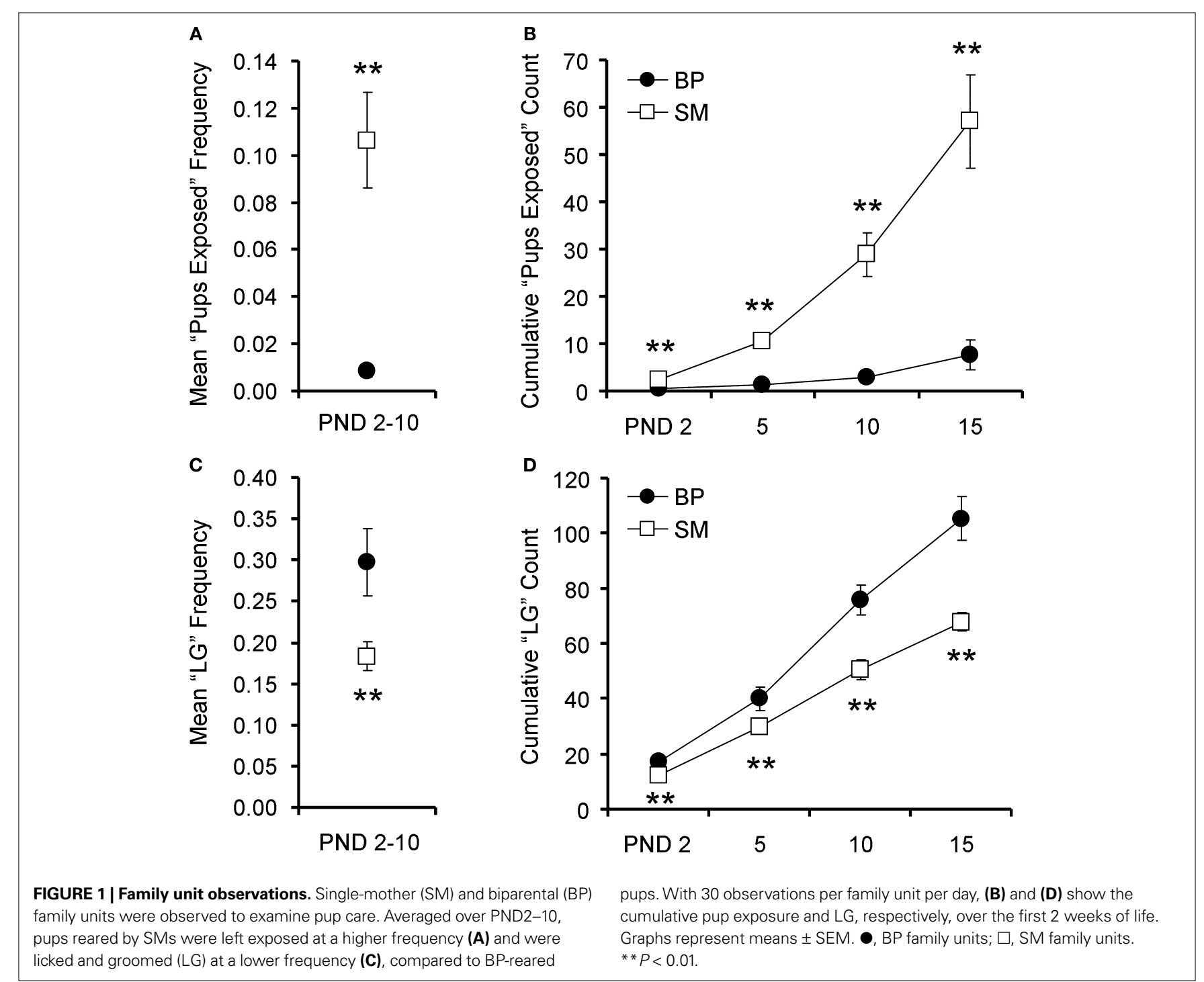


$P<0.001)$, and a PND by rearing condition interaction $\left(F_{1,10}=\right.$ 23.231, $P<0.001)$. Post hoc pair-wise comparisons revealed that SM-reared offspring were cumulatively exposed significantly more than BP-reared offspring, measured at PND2 $(P=0.01$; Figure 1B), PND5 $(P<0.001)$, PND10 $(P<0.001)$, and PND15 $(P<0.001)$.

\section{Licking and grooming}

Pups were considered to have been licked and groomed (LG) if at least one pup within the litter was receiving LG from one of the parents. We again looked at both frequency and cumulative effect. A simple $t$-test revealed that, from PND2-10, the SM-reared offspring experienced a significantly lower frequency of LG than BP-reared counterparts $(P=0.02$; Figure $1 \mathrm{C}$; $\mathrm{BP}=8, \mathrm{SM}=7)$.

Again, a total of twelve family units $(B P=6, S M=6)$ were observed from PND1-15. A 2 (group) $\times 4$ (PND) ANOVA, with $\mathrm{PND}$ as a repeated measure, and cumulative LG as the dependent measure, revealed a main effect of $\operatorname{PND}\left(F_{1,10}=373.572, P<0.001\right)$, rearing condition $\left(F_{1,10}=24.720, P=0.001\right)$, and a PND by rearing condition interaction $\left(F_{1,10}=20.179, P=0.001\right)$. Post hoc pair-wise comparisons revealed that SM-reared offspring were cumulatively LG significantly less than BP-reared counterparts, measured at PND2 $(P<0.01$; Figure 1D), PND5 $(P<0.01)$, PND10 $(P<0.01)$, and PND15 $(P<0.01)$.

To determine if this difference was entirely due to the absence of the male in the SM-group or whether there were differences in the way the mothers interacted with their pups, a second 2 (family unit) $\times 4$ (PND) ANOVA was performed, with PND as a repeated measure and LG provided only by the female as the dependent measure. The analysis revealed a main effect of PND $\left(F_{1,10}=432.314\right.$, $P<0.001)$, but no effect of rearing group $\left(F_{1,10}=0.221, P=0.649\right)$, nor a PND by rearing group interaction $\left(F_{1,10}=0.002, P=0.965\right)$; data not shown.

\section{Pup exploration}

During observations, pups were considered off the nest if at least one pup from the litter had ventured away from the nest using its own power. A simple $t$-test was used to compare cumulative number of pup-off observations across groups at PND15, approximately two-thirds through the pre-weaning period. This simple pair-wise comparison revealed only a trend, with BP-reared animals venturing off the nest more often than SM-reared offspring $(P=0.071$; $\mathrm{BP}=6, \mathrm{SM}=6$; Figure $2 \mathrm{~A}$ ).

\section{Pup weight}

There was a significant main effect of rearing condition on pup weight $\left(F_{1,51}=15.151, P<0.001\right)$, but no sex or rearing-condition by sex interaction effects. Post hoc tests demonstrated that SMreared animals weighed less at weaning than BP-reared animals, regardless of sex $(P<0.01$; Figure 2B). By adulthood (PND60), however, SM-reared animals from both sexes had achieved mass weights statistically indistinguishable from BP-reared animals $(P=0.469)$.

\section{ADULT SPONTANEOUS ALLOPARENTAL CARE Latency to approach}

Mann-Whitney non-parametric analysis revealed no group differences between BP- and SM-reared females $(U=38, P=0.825$; Figure 3A) or males $(U=58, P=0.897$; Figure 3B $)$ in their latency to approach the 2- to 5-day-old, unrelated pups.

\section{Attacks}

Chi-squared analysis revealed that there was also no group difference in the number of animals that attacked for either sex: females (BP-reared: 4/12 versus SM-reared: $1 / 10: \chi^{2}(1)=1.69, P=0.193$ ) or males (BP: $2 / 10$ versus SM: $1 / 12: \chi^{2}(1)=0.630, P=0.427$; data not shown).

\section{Pup-directed behavior}

Mann-Whitney analyses did reveal significant group differences in pup-directed care in females. SM-reared females exhibited significantly less LG of pups $(U=8, P=0.005$; Figure $3 \mathrm{~A})$ and less time immobile (huddling) over pups $(U=9, P=0.004)$. Males showed

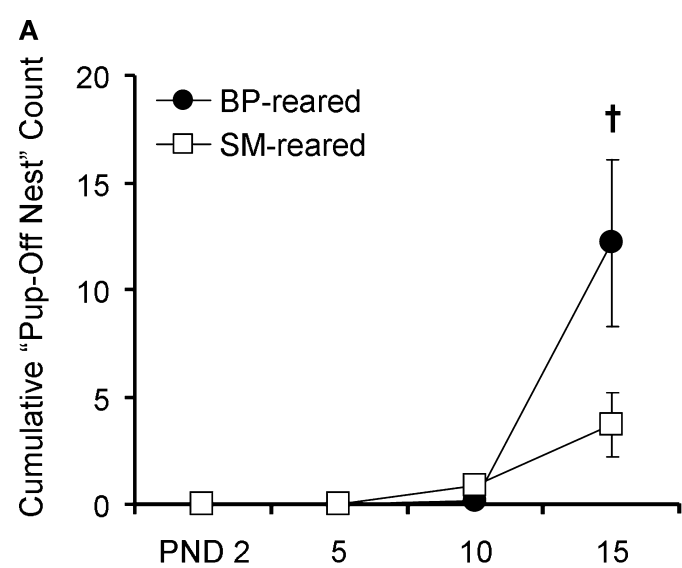

FIGURE 2 | Pup maturation. SM- and BP-reared pups were observed and weighed to obtain maturational measurements. SM-reared pups ventured off the nest less frequently ((A), although this reached only trend level) and weighed less at weaning (B) than BP-reared offspring. SM- and

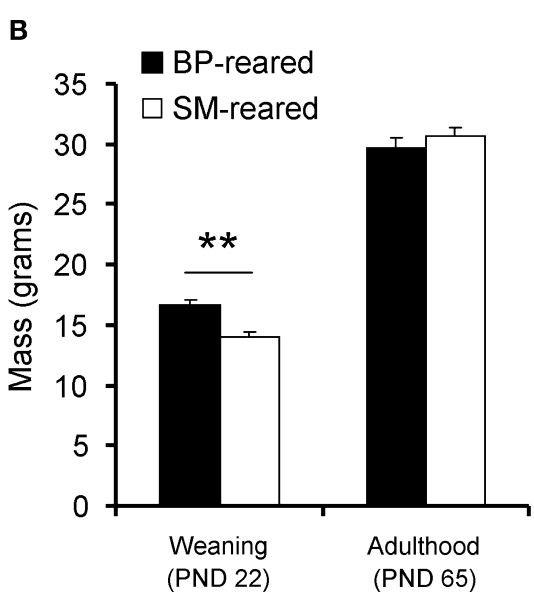

BP-reared animal weights in adulthood were statistically indistinguishable (B). Line graphs represent means \pm SEM; bar graphs represent means + SEM. O/ $\mathbf{\square}$, BP-reared pups; $\square$, SM-reared pups. ${ }^{\dagger} P=0.071,{ }^{*} P<0.01$ 

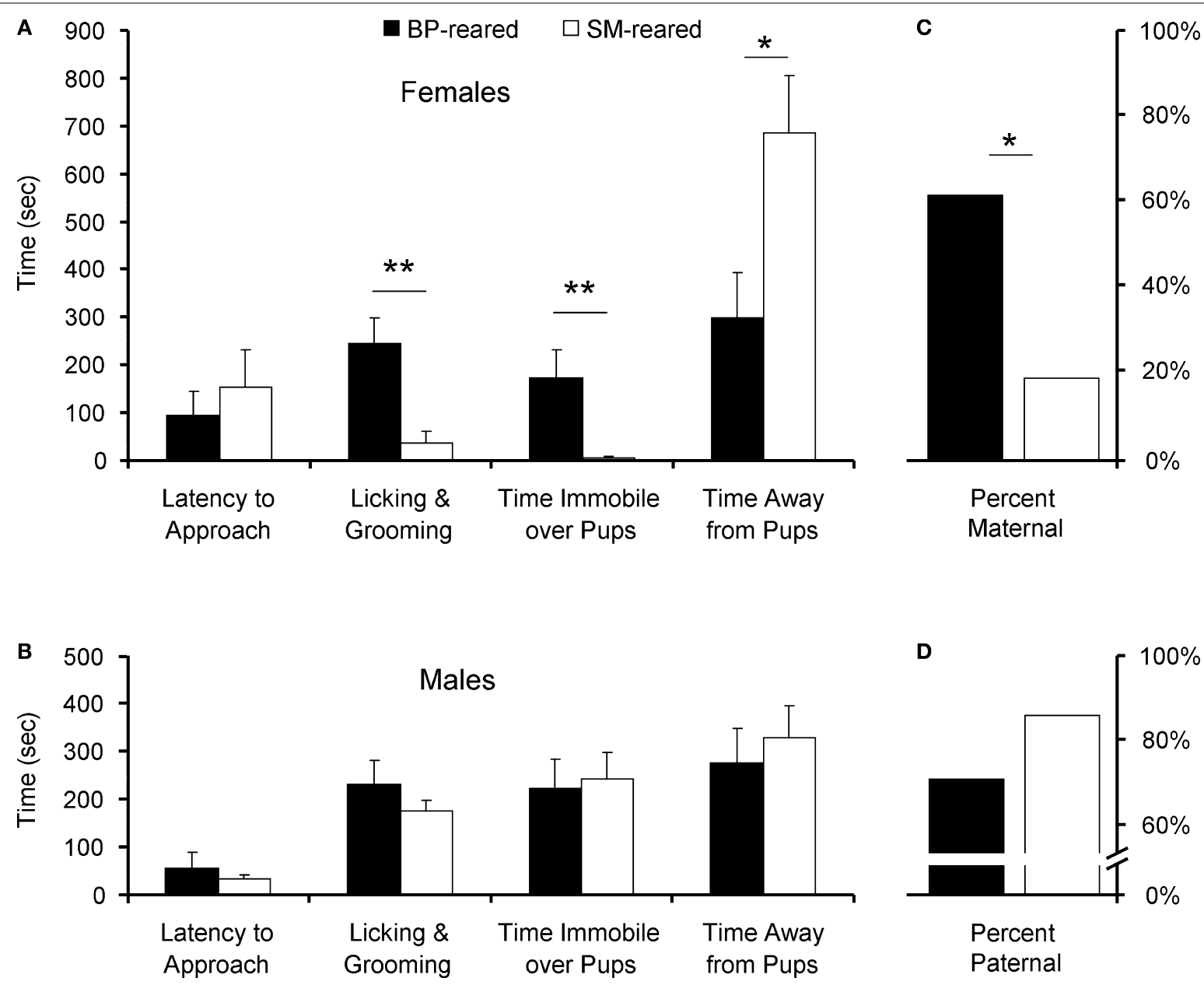

FIGURE 3 | Spontaneous alloparental behavior. SM- and BP-reared adults were tested for spontaneous alloparental nurturing behavior. SM-reared adult female offspring showed significantly lower levels of pup-directed alloparental care (time licking and grooming and time immobile over pups) and spent most of their time away from the pups, in comparison to BP-reared adult females (A). SM- and BP-reared males showed no differences in key measures of alloparental behavior (B). Based on previously published criteria (Lonstein and De Vries, 1999; Olazábal and Young, 2005), individual animals from each sex and group were categorized as spontaneously maternal (C) or spontaneously paternal (D). Bar graphs represent means + SEM (A,B) or mean percentages (C,D). $\mathbf{\square}$, BP-reared adult offspring; $\square$, SM-reared adult offspring. ${ }^{*} P<0.05$, **P $P<0.01$. equal amounts of both LG $(U=45, P=0.357$; Figure 3B $)$ and huddling over pups $(U=58, P=0.925)$ across rearing conditions.

Mann-Whitney analysis also revealed a significant effect of rearing group on the amount of time test animals spent away from pups. SM-reared females spent more time away from the stimulus pups than BP-reared females ( $U=17, P=0.04$; Figure 3A); males showed no group difference $(U=59, P=0.975$; Figure $3 B)$.

\section{Parental versus non-parental}

Many studies of prairie voles categorize individuals as either spontaneously parental or non-parental. Using standard criteria (>, we categorized each of our test subjects. A significantly smaller percentage of SM-reared females were spontaneously maternal compared to BP-reared females: 17 versus $60 \%$, respectively $\left(X^{2}(1)=4.43\right.$, $P=0.035$; Figure 3C). SM- and BP-reared males did not differ, with 83 and $70 \%$ categorized as spontaneously paternal, respectively $\left(X^{2}(1)=0.55, P=0.457\right.$; Figure 3D).

\section{ADULT PARTNER PREFERENCE FORMATION Cohabitation mating}

Mating facilitates PP formation in prairie voles, but is not necessary given a $24 \mathrm{~h}$ cohabitation period, although this varies across laboratories (Carter et al., 1995; Young and Wang, 2004). After $24 \mathrm{~h}$ of cohabitation, our crude visual method of mating analysis showed that experimental groups from cohort 3 did not differ in the number of animals that showed indications of mating after $24 \mathrm{~h}$ (mated/total: BP-reared females (1/12) versus SMreared females $(3 / 12): \chi^{2}(1)=1.2, P=0.273$; BP-reared males $(2 / 12)$ versus SM-reared males $\left.(3 / 12): \chi^{2}(1)=0.253, P=0.615\right)$ and after $48 \mathrm{~h}$ of cohabitation (BP-reared females $(8 / 12)$ versus SM-reared females $(8 / 12): \chi^{2}(1)=0, P=1$; BP-reared males $(10 / 12)$ versus SM-reared males $\left.(7 / 12): \chi^{2}(1)=1.815, P=0.178\right)$. It is important to note that similar non-differences were observed if different criteria were used (e.g. only redness, only vaginal opening). 


\section{Partner preference testing}

Cohort $3 \mathrm{BP}$ - and SM-reared animals were assessed in the PP test at 3 time points: after $24 \mathrm{~h}$, after $48 \mathrm{~h}$, and after 1 week of total cohabitation time. A 2 (stimulus animal) $\times 2$ (group) $\times 2($ sex $) \times 3$ (time point) ANOVA, with time huddling as the dependent measure and with cohabitation period as a repeated measure, revealed a main effect of stimulus animal (partner versus stranger; $F_{1264}=60$, $P<0.001)$, a main effect of sex $\left(F_{1264}=4.2, P<0.04\right)$, and a group by stimulus interaction $\left(F_{1,262}, P<0.02\right)$.

After splitting by sex and group, planned post hoc pair-wise comparisons were used to compare time spent huddling with partner versus stranger in order to assess PP formation. A significant PP was observed after $24 \mathrm{~h}, 48 \mathrm{~h}$, and at 1 week of cohabitation for both BP-reared females (Partner $>$ Stranger: $24 \mathrm{~h}: P=0.014$;
48 h: $P=0.015$; 1 week: $P<0.001$; Figure 4A) and BP-reared males (Partner $>$ Stranger: 24 h: $P=0.04 ; 48$ h: $P=0.001 ; 1$ week: $P=0.002$; Figure 4B). SM-reared animals, on the other hand, did not show this same PP formation profile: Both SM-reared females (Figure 4A) and males (Figure 4B) failed to show a significant PP at 24 and $48 \mathrm{~h}$, but did reach significance by 1 week (SM-reared females: Partner > Stranger: 24 h: $P=0.250 ; 48$ h: $P=0.186 ; 1$ week: $P=0.006$; SM-reared males: Partner $>$ Stranger: 24 h: $P=0.414$; 48 h: $P=0.450$; 1 week: $P=0.044)$.

\section{OPEN-FIELD TEST}

Cohort 2 animals underwent open-field testing for $20 \mathrm{~min}$. To account for longitudinal changes in behavior over time and to allow comparison with typical $5 \mathrm{~min}$ open-field test studies, the

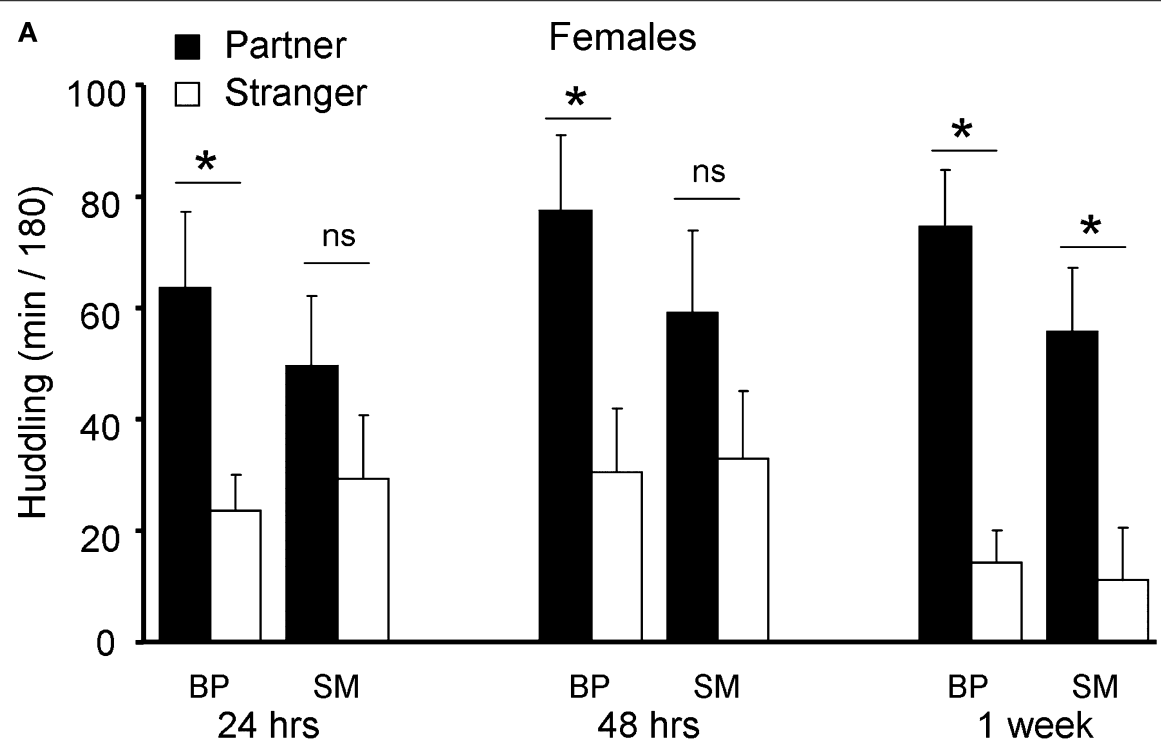

B

Males

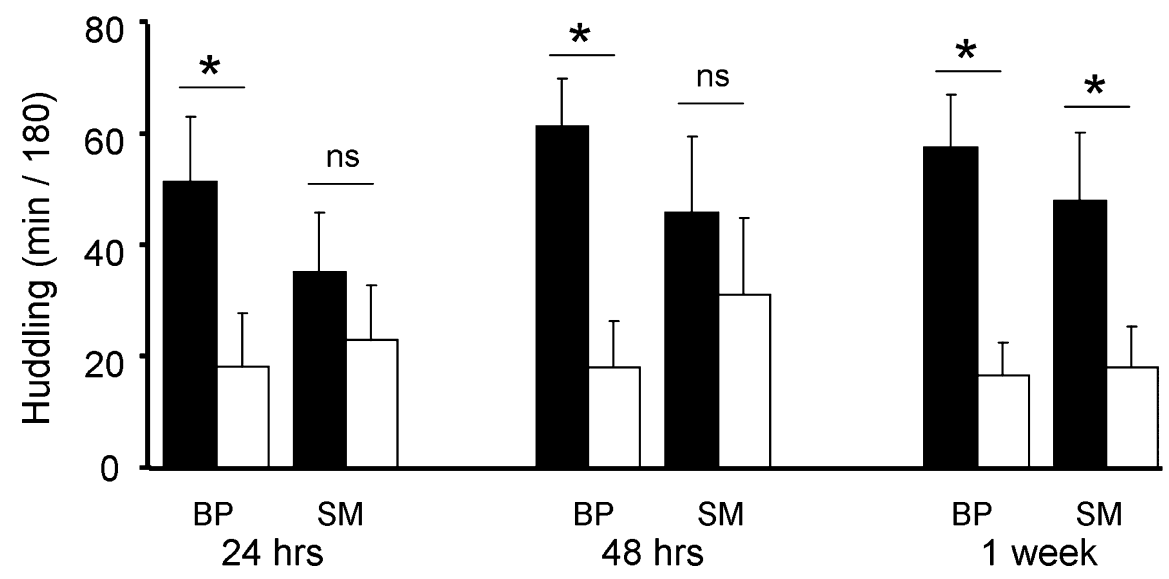

FIGURE 4 | Partner preference testing. SM- and BP-reared adults were tested for social bonding behavior in the partner preference test at three time-points throughout cohabitation: 24 h, 48 h, and 1 week post-pairing. SM-reared adult females exhibited a slower onset of partner preference formation compared to BP-reared adult females (A), with BP-reared females demonstrating significant group partner preferences at all three time-points and SM-reared females only during the 1-week test. SM-reared adult males also exhibited a slower onset of partner preference formation compared BP-reared adult males (B), again, with BP-reared males showing significant group partner preferences during all three time points, while SM-reared males demonstrated a significant partner preference only at 1 week. Bar graphs represent means + SEM. $\mathbf{\square}$, BP-reared adult offspring; $\square$, SM-reared adult offspring. ${ }^{*} P<0.05$, ns $=$ not significant. 
total time was divided into 5-min intervals. The first ( $0-5 \mathrm{~min})$ and last (15-20 $\mathrm{min}$ ) 5-min intervals were used for statistical analysis: the initial period represents a locomotor response to novelty, while the last approximates general activity. Time spent in the inner $10 \mathrm{~cm} \times 10 \mathrm{~cm}$ zone and total distance moved were scored to analyze anxiety and locomotor activity, respectively.

\section{Time in center}

Due to non-normality of the time spent in the center, all subsequent analyses were performed after a square-root transformation. A 2 (time interval: $0-5 \mathrm{~min}$ versus $15-20 \mathrm{~min}) \times 2$ (group) $\times 2($ sex $)$ ANOVA, where interval was a repeated measure and time in the center was the dependent variable, revealed a main effect of time interval $\left(F_{1,40}=29.43, P<0.001\right)$ and a sex difference $\left(F_{1,40}=4.24\right.$, $P=0.045)$, but no group effect $\left(F_{1,38}=0.137, P=0.713\right)$, nor group by sex interaction $\left(F_{1,40}=0.521, P=0.474\right)$. There were no interactions with time interval. Post hoc pair-wise comparisons revealed a significant sex difference during the first 5 min interval $(P=0.004$; Figure 5A), but not during the fourth interval $(P=0.751$; data not shown).

\section{Total distance moved in the open-field}

Again, due to non-normality, all subsequent locomotor activity analyses were performed after a square-root transformation. A 2 (time interval: $0-5 \mathrm{~min}$ versus $15-20 \mathrm{~min}) \times 2$ (group) $\times 2($ sex $)$ ANOVA, with time interval as a repeated measure and distance
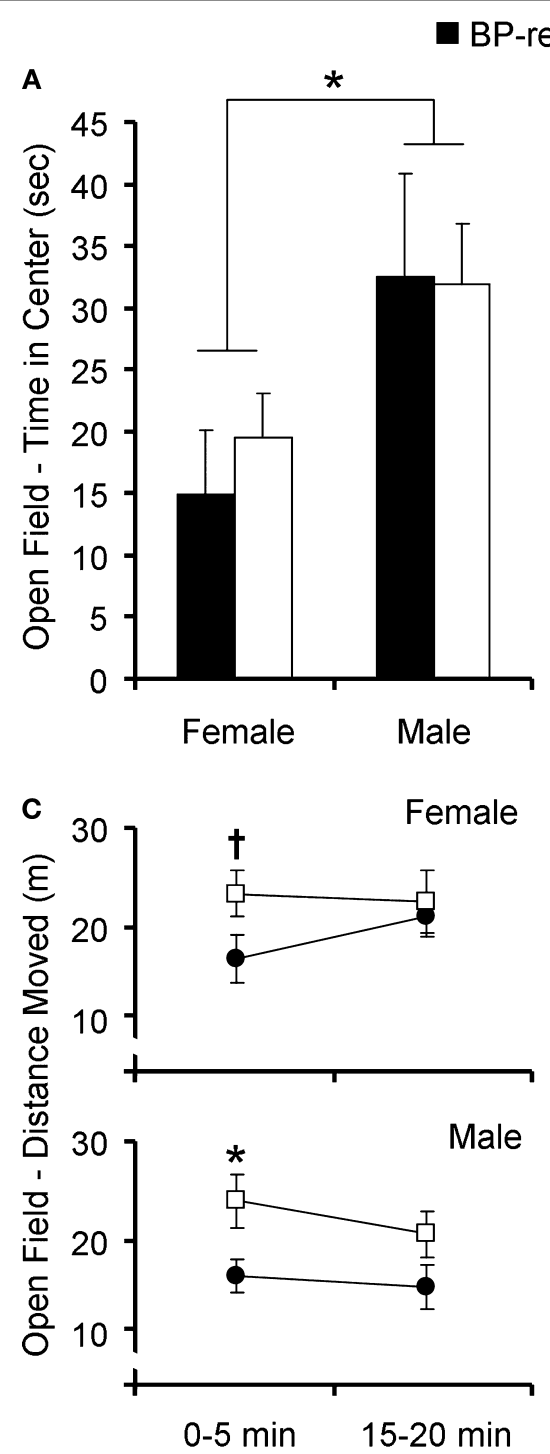

FIGURE 5 | Anxiety behavior and locomotor activity. SM- and BP-reared adults were tested for anxiety and exploratory/locomotor activity in the open-field and elevated plus maze (EPM). SM- and BP-reared adult animals showed no differences in time spent exploring the anxiety-inducing center zone of the open-field (A), but SM-reared animals did spend a greater percentage of time in the anxiety-inducing open-arms of the EPM (B),
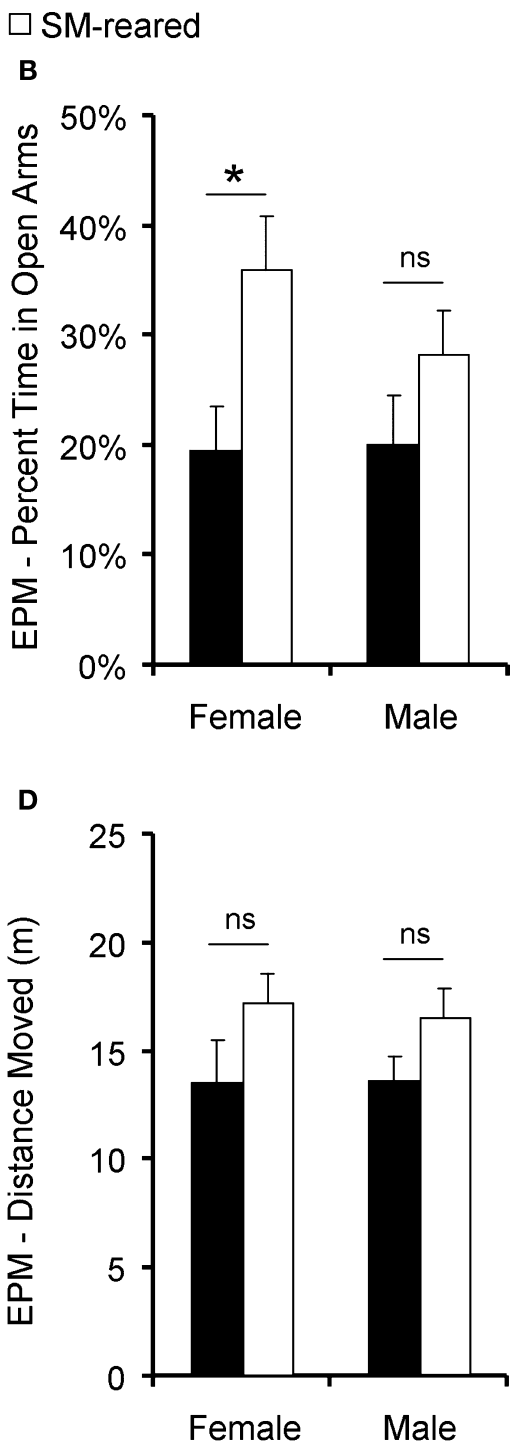

compared to BP-reared adult animals. In terms of locomotor activity, SM-reared adult animals of both sexes showed transient hyperactivity in both the first 5 min of the open-field test (C) and the 5 min EPM test (D), compared to BP-reared counterparts. Bar graphs represent means + SEM. ם, BP-reared adult offspring; $\square$, SM-reared adult offspring. ${ }^{*} P<0.05$, $\mathrm{ns}=$ not significant. 
moved as the dependent variable, revealed a main effect of group $\left(F_{1,40}=4.949, P=0.031\right.$; Figure $\left.5 \mathrm{C}\right)$, but no effect of sex nor interval. There were no interactions. Post hoc tests revealed that both male and female SM-reared offspring moved a greater distance during the first $5 \mathrm{~min}$ interval than their BP-reared counterparts ( $P=0.038$ and $P=0.056$, respectively), although the effect was only a trend in females. The difference disappeared in both sexes by the $15-20 \mathrm{~min}$ interval $(P=0.141$ and $P=0.831$, respectively; data not shown).

\section{ELEVATED PLUS MAZE}

Animals underwent EPM testing for $5 \mathrm{~min}$. Raw time in each zone (open-arms, closed-arms, and center) and total distance moved was scored. Anxiety-related measures were then calculated.

\section{Percentage time in open arms}

The percentage of time spent in the open arms was calculated [open arm time/(open arm time + closed arm time)], then tested for normality and homogeneity of variance. Raw scores were nonnormal, so the data were square-root transformed. A two-factor ANOVA revealed that there was a main effect of group $\left(F_{1,38}=7.13\right.$, $P=0.011$; Figure 5B), but no effect of sex, nor was there a group by sex interaction. Post hoc pair-wise comparisons revealed that SM-reared females, but not males, spent a greater percentage of time in the open arms compared to BP-reared controls $(P=0.015$ and $P=0.202$, respectively).

\section{Total distance moved in EPM}

Raw total locomotor activity data were square-root transformed to achieve normality and then analyzed. A two-factor ANOVA revealed a main effect of group $\left(F_{1,38}=5.89, P=0.019\right.$; Figure 5D), but no effect of sex, nor was there a group by sex interaction. Planned post hoc testing revealed that SM-reared offspring moved more throughout the entire EPM BP-reared animals $(P=0.012)$, but effects did not remain significant when each sex was analyzed separately: females $P=0.112$; males $P=0.088$.

\section{Percentage of open arm entries}

The percentage of open arm entries was also calculated [open arm entries/(open arm entries + closed arm entries)], tested for normality and homogeneity of variance, square-root transformed, and then analyzed using a two-factor ANOVA. The ANOVA revealed no difference in group $\left(F_{1,38}=0.157, P=0.694\right)$ nor sex $\left(F_{1,38}=0.610\right.$, $P=0.439)$, nor was there a group by sex interaction $\left(F_{1,38}=0.544\right.$, $P=0.465)$; data not shown.

\section{BASAL PLASMA CORTICOSTERONE}

We extracted and examined basal corticosterone concentrations from adult cohort 1 offspring reared under SM or BP conditions. Due to non-normality of the raw corticosterone plasma concentrations $(\mathrm{ng} / \mathrm{mL})$, animals were segregated by sex first and then group differences were analyzed using separate non-parametric tests. Mann-Whitney $U$ analysis revealed no group differences in baseline plasma corticosterone concentrations for both females $[U=11, P=0.262: \mathrm{BP}=910 \pm 250$ (mean $\pm \mathrm{SEM}) \mathrm{ng} /$ $\mathrm{mL} ; \mathrm{SM}=492 \pm 106 \mathrm{ng} / \mathrm{mL}]$ and males $(U=17, \quad P=0.873$ : $\mathrm{BP}=599 \pm 202 \mathrm{ng} / \mathrm{mL} ; \mathrm{SM}=418 \pm 106 \mathrm{ng} / \mathrm{mL})$.

\section{OXYTOCIN EXPRESSION}

\section{Number of OT mRNA clusters}

OT mRNA was detected using in situ hybridization and emulsion dipping. Dense silver-grain clusters were counted in five adjacent sections throughout the PVN using dark-field microscopy (Young et al., 1994). A 2 (group) by 2 (sex) ANOVA, with PVN OT mRNA clusters as the dependent measure, revealed a main effect of group $\left(F_{1,20}=4.72, P=0.042\right.$; Figure 6A), but no effect of sex $\left(F_{1,20}=0.28, P=0.60\right)$ nor group by sex interaction $\left(F_{1,20}=0.19, P=0.67\right)$. Planned post hoc comparisons within each sex demonstrated that $\mathrm{SM}$-reared females had significantly greater numbers of OT mRNA clusters in the PVN than BP-reared females $(\mathrm{t}(10)=-3.1, P=0.01)$, whereas males showed no statistical difference $(\mathrm{t}(10)=-0.96, P=0.361)$.

For a more detailed analysis, we subdivided the PVN and found that the anterior portion demonstrated the most striking group difference, again with SM-reared females having substantially more OT mRNA clusters than BP-reared counterparts $(\mathrm{t}(10)=-3.62$, $P=0.005$; Figures 6A-I).

\section{OT mRNA grains per cluster}

After dark-field cluster counts had been performed, individual grains/cluster were counted over large neuron nuclei. This quantification estimates a measure of mRNA production on a cell by cell basis. A 2 (group) by 2 (sex) ANOVA, with PVN OT mRNA silvergrains per cluster as the dependent measure, revealed no significant main effects or interactions (Figures 6J-L): group $\left(F_{1,20}=0.544\right.$, $P=0.469)$, sex $\left(F_{1,20}=0.662, P=0.426\right)$, group $\times$ sex interaction $\left(F_{1,20}=0.017, P=0.897\right)$.

\section{NEUROPEPTIDE RECEPTOR DENSITIES Ventral forebrain}

A 2 (group) $\times 2$ (sex) $\times 4$ (receptor type) ANOVA, with receptor type as a repeated measure, and binding density for OTR in the shell of the nucleus accumbens (NAcc-Shell), V1aR in the ventral pallidum, CRF1 in the NAcc-shell, and CRF2 in the NAcc septal pole as the dependent measures. The analysis revealed a significant effect of receptor type $\left(F_{1,20}=81.378, P<0.001\right)$, but no effect of $\operatorname{sex}\left(F_{1,20}=0.097, P=0.759\right)$ nor group $\left(F_{1,20}=1.091, P=0.309\right)$; there was also no group by sex interaction $\left(F_{1,20}=0.542, P=0.470\right)$. $\mathrm{BP}$ - and SM-reared adults did not significantly differ in any of the four neuropeptide receptor type in any of ventral forebrain regions examined (Figure 7A).

\section{Oxytocin receptor}

We performed a second tier analysis that investigated the effect of rearing condition on four to five other brain regions that express high (and often variable) densities of neuropeptide receptors and are known to either underlie certain social behaviors or be affected by early life experience. Each set of regions for each receptor type was analyzed using a separate MANOVA.

A 2 (group) $\times 2(\operatorname{sex})$ MANOVA for OTR binding density in the lateral bed nucleus of the stria terminalis (IBNST), lateral septum (LS), medial preoptic area (MPOA), central amygdala (cAmyg), and basolateral amygdala (BLA) revealed no group effect for any of the brain regions (Table 2). The lBNST, however, showed a nearsignificant trend $\left(F_{1,24}=4.281, P=0.052\right)$. The MANOVA also 

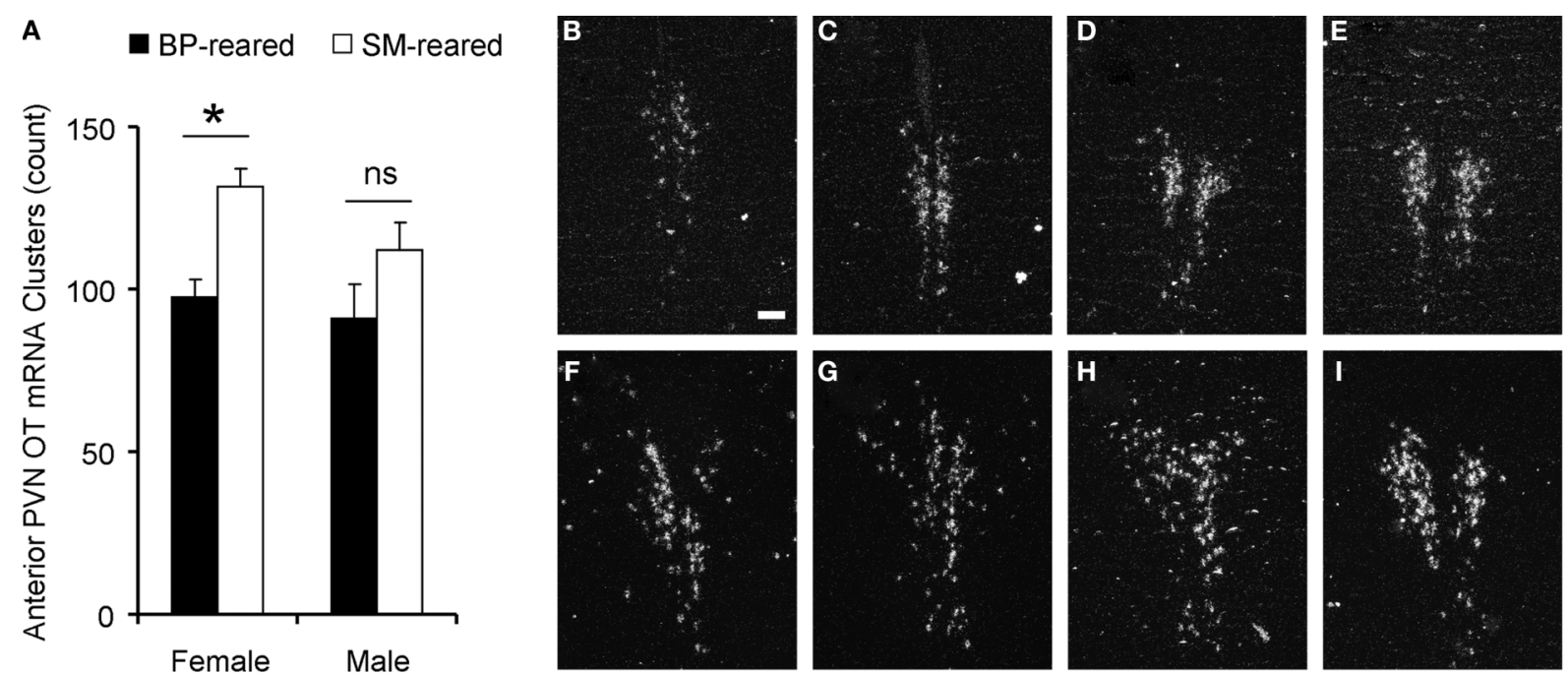

$\mathbf{J}$
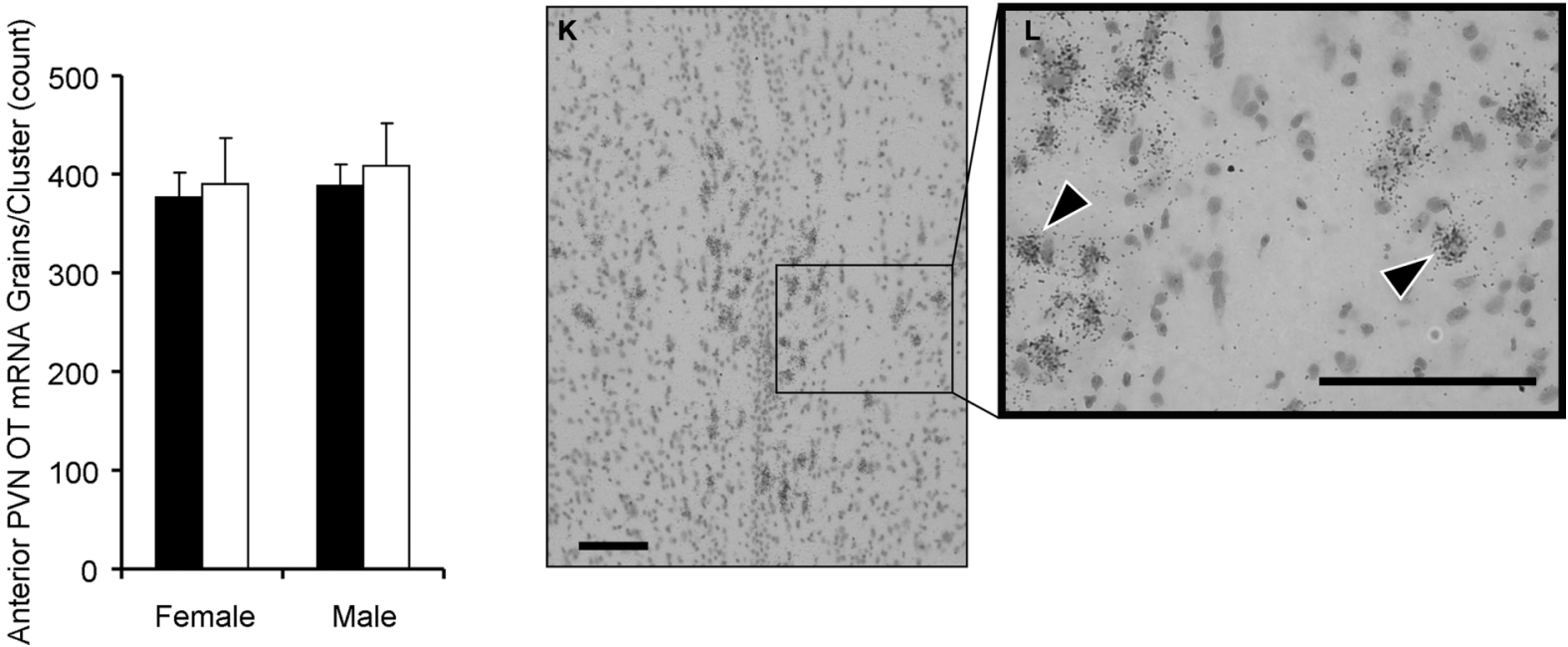

FIGURE 6 | Oxytocin content in the paraventricular nucleus of the hypothalamus (PVN). Brains were extracted from behaviorally-naiive SM- and BP-reared adults and analyzed for oxytocin (OT) mRNA expression using in situ hybridization and emulsion dipping. SM-reared animals had a significantly greater number of OT mRNA grain clusters throughout the PVN, particularly in the anterior portion, compared to BP-reared animals (A). Representative, anterior to posterior, coronal, 10x images of the PVN of SM- (B-E) and BP- (F-I) reared females, under dark-field conditions, show grain clusters. OT expression was also analyzed by counting the number of grains per cluster over large nuclei. There were no group differences in grains per cluster (J). (K) and (L) are representative images of PVN clusters over large nuclei at 20x and 40x, respectively. Arrow-heads (L) identify clustered grains and scale bars represent $100 \mu \mathrm{M}(\mathbf{B}, \mathbf{K}, \mathbf{L})$. $\mathbf{\square}, \mathrm{BP}$-reared adult offspring; $\square$, SM-reared adult offspring. ${ }^{*} P<0.05$, ns $=$ not significant. revealed a sex effect in the cAmyg $\left(F_{1,24}=7.970, P=0.011\right)$ and BLA $\left(F_{1,24}=6.054, P=0.023\right)$, but no group by sex interaction. Post hoc pair-wise comparisons revealed that, regardless of group, females expressed a greater density of OTR than males in the both the cAmyg $(P=0.018)$ and BLA $(P=0.008)$; data not shown. An exploratory post hoc $t$-test for IBNST revealed that SM-reared offspring had a lower density of OTR than BP-reared animals $(P=0.049)$.

\section{Vasopressin 1a receptor}

A 2 (group) $\times 2$ (sex) MANOVA for V1aR binding density in LS, BNST, mediodorsal thalamus (MDThal), cAmyg, and posterior cingulate revealed no main effects of group or sex, nor a group by sex interaction for any of the brain regions (Table 2).

\section{Corticotropin-releasing factor receptor 1}

A 2 (group) $\times 2$ (sex) MANOVA for CRF1 binding density in the medial prefrontal cortex (mPFC), LS, BLA, and cAmgy revealed no group effect for any of the brain regions, but there was a main effect of sex in the $\operatorname{mPFC}\left(F_{1,24}=5.224, P=0.033\right)$. There were no interactions (Table 2).

\section{Corticotropin-releasing factor receptor 2}

Lastly, a 2 (group) $\times 2$ (sex) MANOVA for CRF2 receptor binding density in the LS, BNST, dorsal raphe (DR), and ventral tegmental area (VTA) revealed a main effect of group for the $\mathrm{DR}\left(F_{1,24}=6.089\right.$, $P=0.032)$ and a main effect of sex for the BNST $\left(F_{1,24}=31.560\right.$, $P<0.001)$. Post hoc testing revealed that, regardless of group, males 

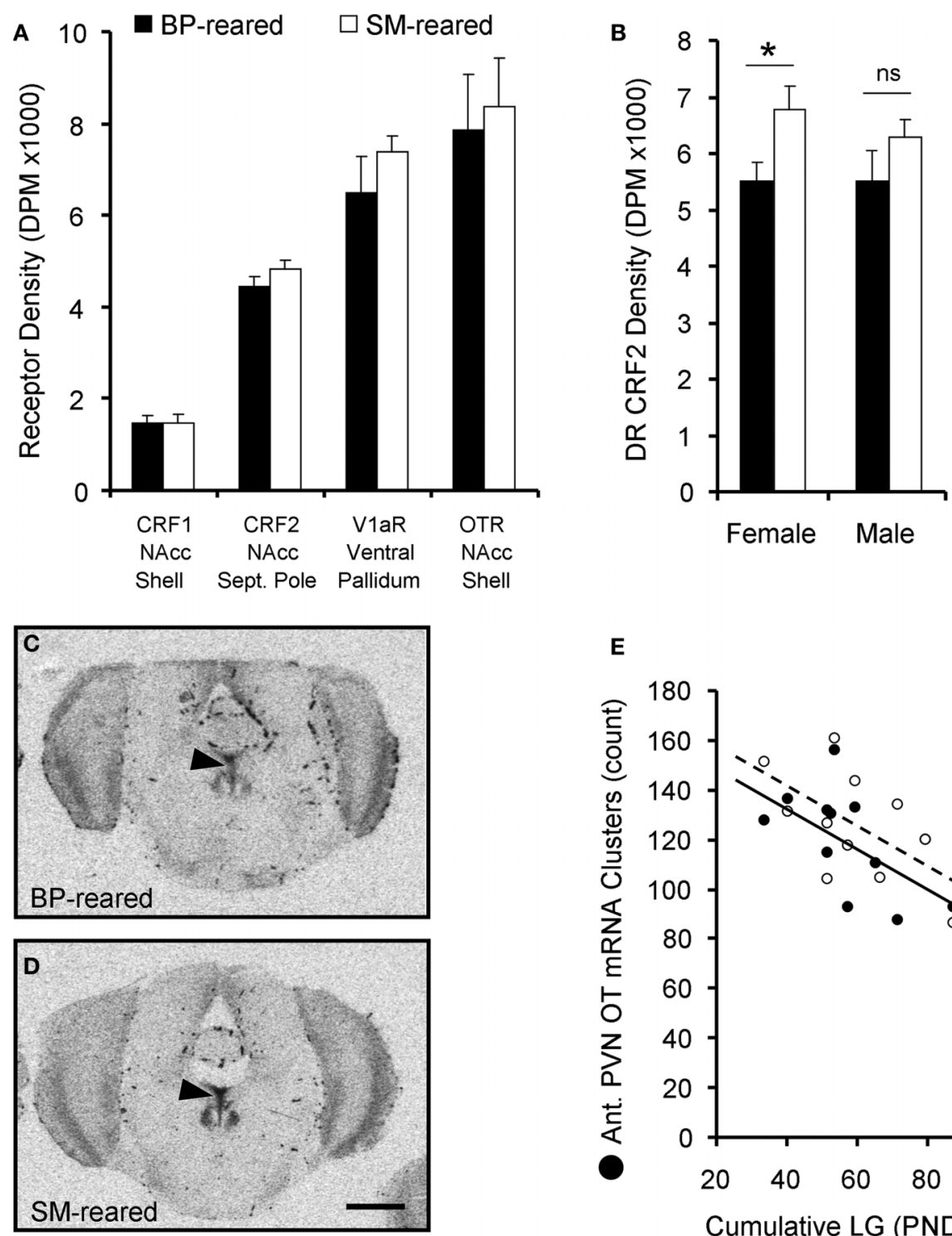

FIGURE 7 | Neuropeptide receptor densities. Brains from behaviorally-naïve SM- and BP-reared adults were assayed for oxytocin receptor (OTR), V1aR, corticotropin-releasing factor receptor 1 (CRF1) and CRF2 using radioligand receptor binding. None of the four neuropeptide receptors showed an effect of rearing condition in socially-relevant ventral forebrain regions $(\mathbf{A})$; NAcc = nucleus accumbens. SM-reared adult animals, particularly females, revealed a higher density of CRF2 in the dorsal raphe (DR), compared to BP-reared animals (B). (C)

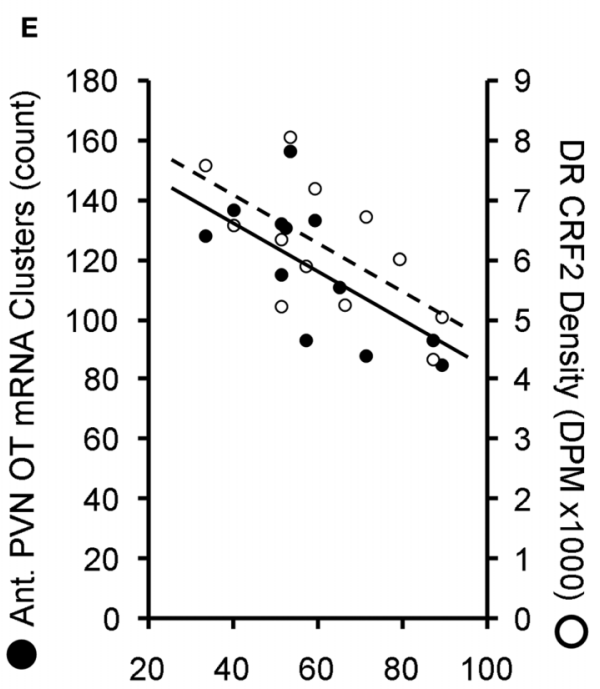

Cumulative LG (PND1-10)

and (D) show representative coronal sections of dorsal raphe CRF2 from BP-and SM-reared females, respectively. Arrow-heads identify the DR and scale bar represents $1 \mathrm{~mm}$. (E) graphically depicts the correlational relationship between early life licking and grooming (LG) and two neuropeptide system markers: the number OT mRNA clusters in the anterior PVN and the density of CRF2 in the DR. $\mathbf{\square}$, BP-reared adult offspring; $\square$, SM-reared adult offspring. $\bullet$, LG/OT correlation $(R=-0.611)$; O, LG/CRF2 correlation $(R=-0.652) .{ }^{*} P<0.05, \mathrm{~ns}=$ not significant.

expressed a greater density of CRF2 in the BNST than females $(P<0.001)$, which replicates a sex difference previously described in prairie voles (Lim et al., 2005). Post hoc testing also demonstrated that SM-reared offspring, regardless of sex, expressed a greater density of CRF2 in the dorsal raphe than BP-reared offspring $(P=0.019$; Table 2, Figure 7B). Representative sections of BP- and SM-reared females are presented in Figures 7C,D, respectively.

\section{EARLY LIFE EXPERIENCE AND NEUROPEPTIDE SYSTEMS}

All of these neuropeptide system analyses occurred using brains extracted from adult animals for which we had extensive early life

experience data (see Figure 1). This allowed us to investigate if particular early life metrics could predict a certain degree of variation in brain expression of OT and CRF2.

First, a bivariate Pearson's correlation revealed that, in females, the number of OT mRNA clusters in the anterior PVN positively correlates with the density of CRF2 in the dorsal raphe $(R=0.626$, $P=0.039)$, while in males there was no relationship $(R=-0.020$, $P=0.952)$.

Second, we investigated the relationship between early life variables and adult neuropeptide system expression. During early life, individual pups were not marked, so our LG data represented how 
Table 2 | Autoradiographic receptor binding densities.

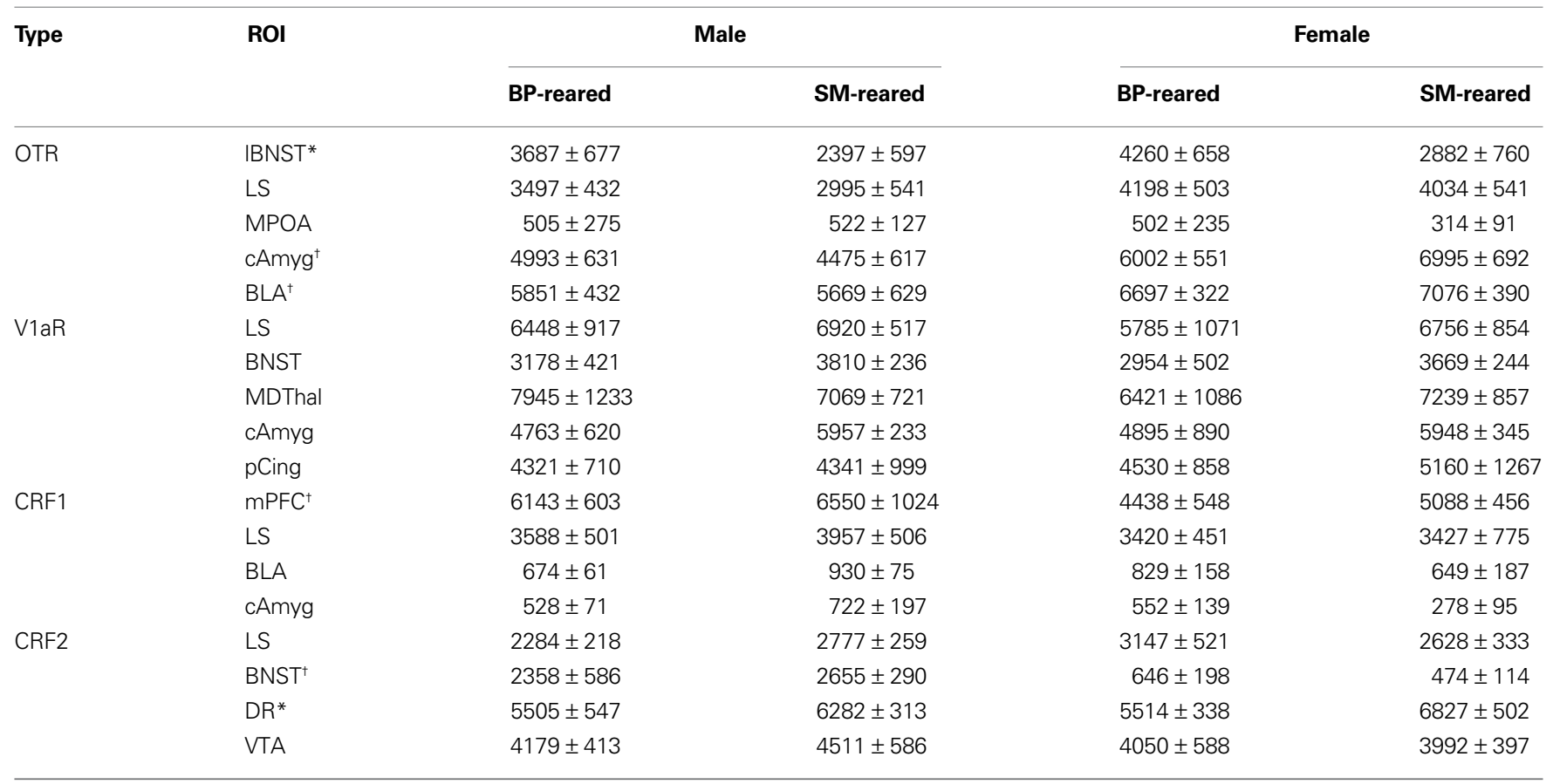

Data are expressed as means \pm SEM.

${ }^{*} P<0.05$ group difference, ${ }^{t} P<0.05$ sex difference.

often at least one of the pups within the litter was being licked and groomed. While not a perfect early life metric, we calculated the accumulated number of LG observations from PND1-10 $\left(\mathrm{LG}_{\mathrm{PND} 10}\right)$ for each litter and allotted that value to the test subject that had been drawn from that litter. We then correlated that value with OT mRNA and CRF2 receptor data from those same individuals. Bivariate correlational analyses revealed that $\mathrm{LG}_{\mathrm{PND} 10}$ significantly correlated with both the number of OT mRNA clusters $(R=-0.611$, $P=0.035$; Figure 7E) and DR CRF2 density $(R=-0.652, P=0.030$; Figure 7E) in females.

\section{DISCUSSION}

In humans and other mammalian species, early life experience can profoundly influence long-term behavior, leading to marked individual variation (Meaney, 2001). There is also a vast psychological literature describing the effects of early parent-offspring interactions and the quality of adult relationships (Bowlby, 1973; Sable, 2004). On average, prairie voles are highly affiliative, but there is remarkable diversity in social behavior across individuals, and this behavioral diversity has been associated with variation in neurochemistry (Phelps and Young, 2003; Young and Wang, 2004; Hammock and Young, 2005; Ophir et al., 2008a,b). In this study, we exploited natural variations in family structure (Getz and Carter, 1996) to examine the connection between early social environment and the expression of species-typical social behaviors, including spontaneous nurturing and social attachment. We compared animals that had been reared by SM and animals that had been reared biparentally (BP). Our findings demonstrate that, as predicted, SM- and BP-reared animals experienced different levels of care during the neonatal period and that these differences significantly influenced alloparental and bonding social behaviors in adulthood.

Most prairie vole offspring receive substantial care from both the mother and the father, with males exhibiting many of the same nurturing behaviors as females (Lonstein and De Vries, 2000). This paternal investment sets voles apart from standard laboratory rodents, such as rats and mice, but is comparable in many respects to other socially monogamous species such as California mice (Dudley, 1974; Bester-Meredith and Marler, 2003; Bredy et al., 2004; Frazier et al., 2006), titi monkeys (Kleiman, 1977; Anzenberger, 1988), and humans (Kleiman, 1977). We hypothesized that removing the male would have significant consequences on the quantity and quality of care received by offspring. Detailed observational comparisons of SM and BP family units revealed that SM-reared pups experienced significantly less care, including greater exposure (Figure 1A) and less LG (Figure 1B) in comparison to BP-reared counterparts.

Importantly, these differences were not a function of blatant neglect on the part of SMs. On average, SM-reared pups were left unattended only $10 \%$ of the time (Figure 1A), and rarely were SM litters exposed for more than three consecutive observations (15-18 $\mathrm{min}$ ), paralleling exposure intervals experienced regularly by other SM-reared rodents such as rats (Caldji et al., 1998; Meaney, 2001). In terms of LG, mothers neither lowered nor increased their maternal investment in response to the presence or absence of the father; SM and BP mothers provided LG at essentially equal rates. Group differences in pup-care instead arose as a function of the father's presence in the BP group. With the assistance of the father, BP-reared pups were unattended less than $1 \%$ of the time (Figure 1B). This remarkable rarity in pup 
exposure is consistent with prairie vole observations over PND1-3 in seminatural environments (McGuire et al., 2007) and suggests that, even if SMs only left the nest to eat and drink, they would be unable to compensate completely for the father's absence.

The effects of rearing on social behavior were dramatic. Compared to BP-reared animals, SM-reared adult females exhibited remarkably low spontaneous alloparental behavior (Figure 3) and both males and females exhibited a delayed onset of PP formation (Figure 4).

Spontaneous alloparental behavior is variable across mammalian species and sexes. For example, among adult rats, both males and females are typically infanticidal, whereas in mice, males are often infanticidal but females of most strains are spontaneously maternal (Lonstein and De Vries, 2000). In prairie voles, however, the majority of adults from both sexes are alloparental. There is, however, substantial individual variation within colonies and variation across laboratories (Roberts et al., 1998; Lonstein and Fleming, 2002; Olazábal and Young, 2005, 2006b). Here we extend work showing that the absence of the father can significantly decrease spontaneous allo-maternal behavior. Wang and Novak (1992) had found an effect of the father's absence on juvenile alloparental behavior, but this was confounded by the presence of the father during test observations in the BP-reared group. Likewise, Roberts et al. (1998) extended this work to adult weanlings, but only found a non-significant trend based on categorical definitions of responsive versus non-responsive. Our data demonstrate that, in comparison to BP-reared adults, SM-reared females responded to unrelated pups with equivalent approach latencies, but ultimately engaged in strikingly little pupdirected behavior such as LG and huddling (Figure 3).

These data corroborate studies looking at more artificial early life manipulations. Neonatal infusions of OT, OTR antagonist, and steroids, all alter adult spontaneous alloparental behavior in prairie voles, as does early handling (Roberts et al., 1996; Bales and Carter, 2003a,b; Bales et al., 2004a,b, 2007). In fact, we note that, technically, our BP-reared animals are not identical to standard colony prairie voles. Throughout this study, all pups were handled weekly to obtain weight measurements. Based on previous work, we cannot rule out the possibility that the behavior of BP-reared animals was influenced by this handling. Despite this caveat, adult BP-reared offspring of both sexes showed historically normal levels of spontaneous alloparental behavior from our laboratory, with $60 \%$ of BP-reared females and $70 \%$ of BP-reared males considered spontaneously parental (Figures 3C,D; Olazábal and Young, 2005). In comparison, only $17 \%$ of SM-reared females were spontaneously maternal (Figure 3C), which parallels work by Roberts et al. (1998). This consistency suggests that neither early life handling nor previous testing in the open-field and EPM, accounts for the nurturing behavior we observed.

Our data show for the first time that natural variation in family structure can significantly influence adult bonding behaviors. In the PP test (a well-established laboratory proxy for pair-bonding), SM-reared offspring of both sexes exhibited a delayed onset of PP formation compared to BP-reared animals (Figures 4A,B). Notably, SM-rearing did not obliterate PP formation (Figure 4); it simply increased the likelihood that PP would not be formed during the initial cohabitation periods. There was no indication that this difference was due to an effect on mating, a factor that can influence PP formation (Williams et al., 1992; Young and Wang, 2004). Like alloparental behavior, PP formation is sensitive to a wide range of manipulations, both during the neonatal period and in adulthood (Carter et al., 1995; Insel and Hulihan, 1995; Bales and Carter, 2003b; Bales et al., 2004b, 2007; Young and Wang, 2004; Lim et al., 2007), including handling (Bales et al., 2007). Therefore, it is worth mentioning that, despite pre-weaning weight measurements, BP-reared animals demonstrated historically normal PP formation after a 24-h cohabitation period (Figure 4; Carter et al., 1995; Young and Wang, 2004).

Our data provide ethologically-relevant support for the hypothesis that early life manipulations can alter species-typical adult nurturing and bonding behaviors in monogamous animals (Bales et al., 2007) and demonstrate in another model species that less extreme early life manipulations - in comparison to extended maternal separation or active abuse, for example - can still have profound behavioral consequences (Meaney, 2001). Finally, these findings may provide at least a partial explanation for some of the behavioral diversity observed in both field and laboratory studies of prairie voles and other highly affiliative species, which parallel phenomena reported in humans.

A crucial question remains, however: what is the mechanism by which early life social behavior is transduced into variation in adult social behavior? Did family structure have a direct effect on the neural mechanisms regulating adult social behavior or was altered social behavior simply a secondary effect downstream of peripheral physiological consequences?

The consequences of family structure were apparent even before weaning. Throughout this study, pups were reared in $30 \mathrm{~cm} \times 34 \mathrm{~cm}$ breeding cages, in which parents had easy access to food and water. Yet SM-reared offspring exhibited developmental delays that mirror findings obtained from father-absent offspring reared in substantially larger $\left(1700 \mathrm{~cm}^{2}\right)$ semi-natural environments with seemingly greater foraging demands (Wang and Novak, 1992). We therefore wondered if SM-reared pups were less mature because they were malnourished. Malnutrition would of course impact any interpretation of adult social behavior. A more detailed analysis of the observational data, however, shows that SM-reared pups were attached to their mother and able to nurse at equal - if not higher - rates compared to BP-reared pups, and SM and BP mothers both ate and drank at approximately equal frequencies (data not shown). While we have no data regarding milk quality or quantity, both findings suggest that malnutrition was not the primary cause of the maturational differences.

Another explanation could be social enrichment. In mice, pups reared by SM tend to weigh less than mice reared in communal groups (Sayler and Salmon, 1969). Likewise, rat pups briefly separated from their mother show retarded growth and suppressed responses to growth hormones - a phenomena more associated with "nurturing touch" than food or temperature changes (Kuhn et al., 1978; Kuhn and Schanberg, 1998; Levine, 2001). In our sample, there was a non-significant correlation between cumulative LG and weaning body mass ( $P=0.085$; data not shown), whereas there was no correlation between body mass and cumulative pup exposure $(P=0.495$; data not shown). This indicates that maturational differences may be more the effect of "nurturing touch" than exposure-induced thermoregulatory load. 
Ruling out nutrition and thermoregulation does not mean that early social environment had a direct effect on the neurobiological mechanisms regulating adult social behavior. Evidence from both clinical and basic research indicates that early life experience can "program" stress axes, resulting in altered anxiety and exploratory behavior (Heim et al., 1997; Caldji et al., 1998; Meaney, 2001; Francis et al., 2002; Branchi and Alleva, 2006; Sanchez, 2006). Behaviorally, increased stress responsivity or exploratory behavior could lead to decreased sociality. We tested SM- and BP-reared pups as adults in two standard, laboratory tests of anxiety and locomotor activity, the open-field test and EPM, which have been used previously with prairie voles (Pitkow et al., 2001; Olazábal and Young, 2005; Bosch et al., 2009). Contrary to our predictions based on the rat literature (Caldji et al., 1998; Francis et al., 1999b, 2000, 2002), SM-reared animals, particularly females, were generally less anxious, but marginally more active, than BP-reared animals (Figure 5B). The hyperactivity, however, was short-lived and only tended toward significance in each sex (Figures 5C,D) and typically it is increased stress that inhibits sociality, particularly in females (DeVries et al., 1996). Therefore, while we cannot rule out a specific social-anxiety, general emotional and locomotor profiles seem unable to account fully for the observed differences in social behavior between SM- and BP-reared animals. We also cannot rule out the possibility that, since these cohort 2 animals underwent open-field testing then EPM testing a week later, that there was not some effect of test order.

Unexpectedly, our neurophysiological investigations provided little insight based on our a priori predictions. OT, AVP, and CRF receptor systems are highly variable across individual prairie voles, particularly in the ventral forebrain, and manipulations of these systems, again in the forebrain, produce significant changes in adult social behavior (Pitkow et al., 2001; Lim et al., 2004, 2007; Young and Wang, 2004; Olazábal and Young, 2006a; Donaldson and Young, 2008; Ross et al., 2009). We therefore hypothesized that variation in ventral forebrain neuropeptide receptor densities would track behavioral performance differences, and that this relationship would be a function of parental care. Contrary to these predictions, we found no group differences in the density of OTR, $\mathrm{V} 1 \mathrm{aR}, \mathrm{CRF} 1$, or CRF2 in key ventral forebrain regions (Figure 7A) nor did they correlate with early LG or pup exposure parameters (data not shown).

Our second-tier analysis, however, revealed that the OT and CRF2 neuropeptide systems in other areas are sensitive to natural variations in early care. Compared to BP-reared animals, SM-reared adults had increased OT mRNA clusters in the PVN, a modestly higher density of OTR in the lateral BNST, and a higher density of CRF2 in the caudal dorsal raphe.

Greater sociality is typically associated with a more robust OT system activation (Williams et al., 1992; Carter et al., 1995; Insel and Hulihan, 1995; Young et al., 1996; Young and Wang, 2004). Thus, finding greater PVN OT content in the less social SM-reared animals was initially surprising and paradoxical, but it is consistent with a study demonstrating that even seemingly opposite neonatal manipulations of the OT system both increase the number of OT neurons in the PVN, particularly in females (Yamamoto et al., 2004). Interestingly, OT can be anxiolytic (Yoshida et al., 2009) and artificial increases in OT have been found to lead to transient hyper-exploration in prairie voles (Dharmadhikari et al., 1997). Thus increased OT in SM-reared animals may partially explain the transient hyperactivity and decreased anxiety we observed in this group, particularly in females where the effects were strongest. Whether the effect of early social experience on OT content helps explain differences in adult nuturing and bonding is still unknown and will require further investigation.

The receptor density differences also did not clearly map onto the behavioral differences we observed, but they do fit with the literature. In two studies comparing high- and low-LG rats, Francis and colleagues found their most striking OTR density differences in the lateral BNST, with high-LG subjects expressing more OTR (Francis et al., 2000, 2002). In the current study, BP-reared animals, which had received greater LG, had significantly more IBNST OTR than SM-reared adults. Since OTR in the IBNST has been associated with anxiety and maternal behavior (Francis et al., 2000), lower IBNST OTR in SM-reared animals might have contributed to the observed alloparental and EPM-anxiety differences. Likewise, activation of CRF2 in the dorsal raphe has been implicated in anxiety, fear and escape behaviors (Hammack et al., 2003; Lukkes et al., 2009b), partially through the modulation of serotonin release in the NAcc (Lukkes et al., 2008, 2009a). Currently, however, virtually nothing is known about the role of dorsal raphe CRF2 receptors in mediating prosocial behaviors.

One intriguing finding is the relationship between the OT and CRF2 neuropeptide systems and early life experience. Both appear sensitive to early social context. In prairie voles, post-weaning isolation results in increased PVN OT content (Pan et al., 2009), while in rats 3 weeks of post-weaning isolation results in long-term upregulation of CRF2 in the dorsal raphe, even after a period of resocialization (Lukkes et al., 2009b). We show here that like rats and prairie voles that receive less social input post-weaning, SM-reared animals have both higher PVN OT and higher dorsal raphe CRF2, and both show a significant negative correlation with early LG (Figure 7E). The effects were most exaggerated in females. Coupled with the findings that females showed more robust behavioral differences throughout this study, our data suggest that females are especially sensitive to LG during early life, potentially through its tandem effects on the OT and CRF2 systems. Future research will aim to elaborate this relationship.

Overall, our data may have broader implications. First, there is the ethological angle. Wild prairie voles show striking individual variation in social behavior. Some of this variation is likely accounted for by specific genetic factors, such as the vasopressin receptor la gene (avpr1a; Phelps and Young, 2003; Hammock and Young, 2005; Ophir et al., 2008a,b). But genes are not acting alone. Here we demonstrate that early social experience is also playing an important role. Given the greater foraging demands in natural environments, SM in the wild are likely to spend even less time with their pups. The decrease in adult social contact may have important consequences for adult social behavior of the offspring. In fact, it would be interesting to test the hypothesis that SM reared animals may account for a greater percentage of wandering males or SM nests than BP or communally reared animals - and then identify the adaptive significance.

Our data may also have implications for studying human psychopathology. While speculative, it is worth noting that our 
prairie vole data have several parallels to human borderline personality disorder (BPD). BPD is typically characterized by poor behavioral regulation, impulsivity, and insecure attachment tendencies, which together serve to disrupt and prevent the formation of strong social bonds throughout life (Zanarini and Frankenburg, 1997, 2007; Skodol et al., 2002; Livesley, 2008). Moreover, BPD has been tied to disrupted parental relationships, particularly neglectful fathers (Frank and Paris, 1981; Zanarini and Frankenburg, 2007) and is more prevalent in females (Ekselius et al., 1996). It is therefore an intriguing possibility that prairie voles might serve as an informative animal model for certain aspects of this disorder, just as early life manipulations of rats and monkeys have informed our understanding of the etiology of depression and anxiety disorders.

In conclusion, psychology and ethology have converged to reveal the importance of early social attachments on development, vulnerability to disease, and adult behavior in humans and other social

\section{REFERENCES}

Ahern, T. H., Modi, M. E., Burkett, J. P., and Young, L. J. (2009). Evaluation of two automated metrics for analyzing partner preference tests. J. Neurosci. Methods 182, 180-188.

Anzenberger, G. (1988). The pairbond in the titi monkey (Callicebus moloch): intrinsic versus extrinsic contributions of the pairmates. Folia Primatol (Basel) 50, 188-203.

Aragona, B. J., Liu, Y., Curtis, J. T., Stephan, F. K., and Wang, Z. (2003). A critical role for nucleus accumbens dopamine in partner-preference formation in male prairie voles. J. Neurosci. 23, 3483-3490.

Bales, K. L., and Carter, C. S. (2003a). Sex differences and developmental effects of oxytocin on aggression and social behavior in prairie voles (Microtus ochrogaster). Horm. Behav. 44, 178-184.

Bales, K. L., and Carter, C. S. (2003b). Developmental exposure to oxytocin facilitates partner preferences in male prairie voles (Microtus ochrogaster). Behav. Neurosci. 117, 854-859.

Bales, K. L., Lewis-Reese, A. D., Pfeifer, L. A., Kramer, K. M., and Carter, C. S. (2007). Early experience affects the traits of monogamy in a sexually dimorphic manner. Dev. Psychobiol. 49, 335-342.

Bales, K. L., Pfeifer, L. A., and Carter, C. S. (2004a). Sex differences and developmental effects of manipulations of oxytocin on alloparenting and anxiety in prairie voles. Dev. Psychobiol. 44, 123-131.

Bales, K. L., Abdelnabi, M., Cushing, B. S., Ottinger, M. A., and Carter, C. S. (2004b). Effects of neonatal oxytocin manipulations on male reproductive potential in prairie voles. Physiol. Behav. $81,519-526$.
Bester-Meredith, J. K., and Marler, C. A. (2003). Vasopressin and the transmission of paternal behavior across generations in mated, cross-fostered Peromyscus mice. Behav. Neurosci. 117, 455-463.

Bosch, O. J., Nair, H. P., Ahern, T. H., Neumann, I. D., and Young, L. J. (2009). The CRF system mediates increased passive stress-coping behavior following the loss of a bonded partner in a monogamous rodent. Neuropsychopharmacology 34, 1406-1415.

Bowlby, J. (1973). Separation: Anxiety and Anger. New York, NY, Basic Books.

Branchi, I., and Alleva, E. (2006). Communal nesting, an early social enrichment, increases the adult anxiety-like response and shapes the role of social context in modulating the emotional behavior. Behav. Brain Res. 172, 299-306.

Bredy, T. W., Lee, A. W., Meaney, M. J., and Brown, R. E. (2004). Effect of neonatal handling and paternal care on offspring cognitive development in the monogamous California mouse (Peromyscus californicus). Horm. Behav. 46, 30-38.

Caldji, C., Tannenbaum, B., Sharma, S., Francis, D., Plotsky, P. M., and Meaney, M. J. (1998). Maternal care during infancy regulates the development of neural systems mediating the expression of fearfulness in the rat. Proc. Natl. Acad. Sci. U.S.A. 95, 5335-5340.

Carter, C. S., DeVries, A. C., and Getz, L. L. (1995). Physiological substrates of mammalian monogamy: the prairie vole model. Neurosci. Biobehav. Rev. 19, 303-314.

DeVries, A. C., DeVries, M. B., Taymans, S. E., and Carter, C. S.

species. We show here that manipulations of the prairie vole family structure have significant effects on early life social experience and that these alterations introduce considerable diversity into both social behavior and neurochemistry, which persists into adulthood. Thus the prairie vole may provide an ideal animal model to explore the neurobiological mechanisms underlying the behavioral phenomena that have inspired the rich psychological literature on attachment theory, and may eventually serve as a platform to study gene/environment interaction effects on the social brain, with important implications for human psychosocial development.

\section{ACKNOWLEDGMENTS}

This research was supported by the following grants: MH77776 (L.J. Young), MH064692 (L.J. Young), NSF IBN-9876754, NIH RR00165, and an NIMH training grant MH0732505 (T.H. Ahern). We would also like to acknowledge Lorra Mathews for assistance with animal care and Erika Ahern for her critical reading of the manuscript.

(1996). The effects of stress on social preferences are sexually dimorphic in prairie voles. Proc. Natl. Acad. Sci. U.S.A. 93, 11980-11984.

DeVries, A. C., Guptaa, T., Cardillo, S., Cho, M., and Carter, C. S. (2002) Corticotropin-releasing factor inducessocial preferencesin maleprairie voles. Psychoneuroendocrinology 27, 705-714.

Dharmadhikari,A.,Lee, Y.S., Roberts, R. L. and Carter, C. S. (1997). Exploratory behavior correlates with social organization and is responsive to peptide injections in prairie voles. Ann. N.Y. Acad. Sci. 807, 610-612.

Donaldson, Z. R., and Young, L. J. (2008) Oxytocin, vasopressin, and the neurogenetics of sociality. Science 322 , 900-904.

Dudley, D. (1974). Contributions of paternal care to the growth and development of the young in Peromyscus californicus. Behav. Biol. 11, 155-166.

Ekselius, L., Bodlund, O., von Knorring, L., Lindström, E., and Kullgren, G. (1996). Sex differences in DSM-III-R, Axis II: personality disorders. Pers. Individ. Dif. 20, 457-461.

Francis, D., Diorio, J., Liu, D., and Meaney, M. J. (1999a). Nongenomic transmission across generations of maternal behavior and stress responses in the rat. Science 286, 1155-1158.

Francis, D. D., Champagne, F. A., Liu, D. and Meaney, M. J. (1999b). Maternal care, gene expression, and the development of individual differences in stress reactivity. Ann. N.Y. Acad. Sci. 896, 66-84.

Francis, D. D., Champagne, F. C., and Meaney, M. J. (2000). Variations in maternal behaviour are associated with differences in oxytocin receptor levels in the rat. J. Neuroendocrinol. 12 , 1145-1148.
Francis, D. D., Young, L. J., Meaney, M. J., and Insel, T. R. (2002). Naturally occurring differences in maternal care are associated with the expression of oxytocin and vasopressin (V1a) receptors: gender differences. J. Neuroendocrinol. 14, 349-353.

Frank, H., and Paris, J. (1981). Recollections of family experience in borderline patients. Arch. Gen. Psychiatry 38, 1031-1034.

Frazier, C. R. M., Trainor, B. C., Cravens, C. J., Whitney, T. K., and Marler, C.A. (2006). Paternal behavior influences development of aggression and vasopressin expression in male California mouse offspring. Horm. Behav. 50, 699-707.

Getz, L. L., and Carter, C. S. (1996). Prairie-vole partnerships. Am. Sci. 84, 56-62.

Getz, L. L., Carter, C. S., and Gavish, L. (1981). The mating system of the prairie vole, Microtus ochrogaster: field and laboratory evidence for pair-bonding. Behav. Ecol. Sociobiol. 8, 189-194.

Getz, L. L., McGuire, B., Pizzuto, T., Hofmann, J. E., and Frase, B. (1993). Social-organization of the prairie vole (Microtus ochrogaster).J. Mammal. 74, 44-58.

Grippo, A. J., Gerena, D., Huang, J., Kumar, N., Shah, M., Ughreja, R., and Carter, C. S. (2007). Social isolation induces behavioral and neuroendocrine disturbances relevant to depression in female and male prairie voles. Psychoneuroendocrinology 32, 966-980.

Hammack, S. E., Schmid, M. J., LoPresti, M. L., Der-Avakian, A., Pellymounter, M. A., Foster, A. C., Watkins, L. R., and Maier, S. F. (2003). Corticotropin releasing hormone type 2 receptors in the dorsal raphe nucleus mediate the behavioral consequences 
of uncontrollable stress. J. Neurosci. 23 , 1019-1025.

Hammock, E.A.D., and Young,L. J.(2005). Microsatellite instability generates diversity in brain and sociobehavioral traits. Science 308, 1630-1634.

Heim, C., Owens, M. J., Plotsky, P. M., and Nemeroff, C. B. (1997). The role of early adverse life events in the etiology of depression and posttraumatic stress disorder. Focus on corticotropin-releasing factor. Ann. N.Y. Acad. Sci. 821, 194-207.

Heim, C., Young, L. J., Newport, D. J., Mletzko, T., Miller, A. H., and Nemeroff, C. B. (2008). Lower CSF oxytocin concentrations in women with a history of childhood abuse. Mol. Psychiatry. doi: 10.1038/mp.2008.112. [Epub ahead of print].

Insel, T. R., and Hulihan, T. J. (1995). A gender-specific mechanism for pair bonding: oxytocin and partner preference formation in monogamous voles. Behav. Neurosci. 109, 782-789.

Kleiman, D. G. (1977). Monogamy in mammals. Q. Rev. Biol. 52, 39-69.

Kuhn, C. M., Butler, S. R., and Schanberg, S. M. (1978). Selective depression of serum growth hormone during maternal deprivation in rat pups. Science 201, 1034-1036.

Kuhn, C. M., and Schanberg, S. M. (1998). Responses to maternal separation: mechanisms and mediators. Int. J. Dev. Neurosci. 16, 261-270.

Levine, S. (2001). Primary social relationships influence the development of the hypothalamic-pituitary-adrenal axis in the rat. Physiol. Behav. 73, 255-260.

Lim, M. M., Liu, Y., Ryabinin, A. E., Bai, Y., Wang, Z., and Young, L. J. (2007). CRF receptors in the nucleus accumbens modulate partner preference in prairie voles. Horm. Behav. 51, 508-515.

Lim, M. M., Nair, H. P., and Young, L. J. (2005). Species and sex differences in brain distribution of corticotropinreleasing factor receptor subtypes 1 and 2 in monogamous and promiscuous vole species. J. Comp. Neurol. 487, 75-92.

Lim, M. M., Wang, Z., Olazábal, D. E., Ren, X., Terwilliger, E. F., and Young, L. J. (2004). Enhanced partner preference in a promiscuous species by manipulating the expression of a single gene. Nature 429, 754-757.

Liu, D., Diorio, J., Day, J. C., Francis, D. D., and Meaney, M. J. (2000). Maternal care, hippocampal synaptogenesis and cognitive development in rats. Nat. Neurosci. 3, 799-806.

Livesley, J. (2008). Toward a geneticallyinformed model of borderline personality disorder. J. Pers. Disord. 22, $42-71$.
Lonstein, J. S., and De Vries, G. J. (1999). Comparison of the parental behavior of pair-bonded female and male prairie voles (Microtus ochrogaster). Physiol. Behav. 66, 33-40.

Lonstein, J. S., and De Vries, G. J. (2000). Sex differences in the parental behavior of rodents. Neurosci. Biobehav. Rev. 24, 669-686.

Lonstein, J. S., and De Vries, G. J. (2001). Social influences on parental and nonparental responses toward pups in virgin female prairie voles (Microtus ochrogaster). J. Comp. Psychol. 115, 53-61.

Lonstein, J. S., and Fleming, A. S. (2002). Parental behaviors in rats and mice. Curr. Protoc. Neurosci. Chapter 8 , 8.15 .

Lukkes, J.L., Forster, G. L., Renner, K. J., and Summers, C.H. (2008). Corticotropinreleasing factor 1 and 2 receptors in the dorsal raphé differentially affect serotonin release in the nucleus accumbens. Eur. J. Pharmacol. 578, 185-193.

Lukkes, J. L., Mokin, M. V., Scholl, J. L., and Forster, G. L. (2009a). Adult rats exposed to early-life social isolation exhibit increased anxiety and conditioned fear behavior, and altered hormonal stress responses. Horm. Behav. 55, 248-256.

Lukkes, J. L., Summers, C. H., Scholl, J. L., Renner, K. J., and Forster, G. L. (2009b). Early life social isolation alters corticotropin-releasing factor responses in adult rats. Neuroscience $158,845-855$.

McGuire, B., Parker, E., and Bemis, W. E. (2007). Sex differences, effects of male presence and coordination of nest visits in prairie voles (Microtus ochrogaster) during the immediate postnatal period. Am. Midl. Nat. 157, 187-201.

McGuire, B., Russell, K. D., Mahoney, T., and Novak, M. (1992). The effects of mate removal on pregnancy success in prairie voles (Microtus ochrogaster) and meadow voles (Microtus pennsylvanicus). Biol. Reprod. 47, 37-42.

Meaney, M. J. (2001). Maternal care, gene expression, and the transmission of individual differences in stress reactivity across generations. Annu. Rev. Neurosci. 24, 1161-1192.

Olazábal, D. E., and Young, L. J. (2005). Variability in 'spontaneous' maternal behavior is associated with anxietylike behavior and affiliation in naïve juvenile and adult female prairie voles (Microtusochrogaster).Dev. Psychobiol. 47, 166-178.

Olazábal, D. E., and Young, L. J. (2006a). Oxytocin receptors in the nucleus accumbens facilitate 'spontaneous' maternal behavior in adult female prairie voles. Neuroscience 141, 559-568.
Olazábal, D. E., and Young, L. J. (2006b) Species and individual differences in juvenile female alloparental care are associated with oxytocin receptor density in the striatum and the latera septum. Horm. Behav. 49, 681-687.

Ophir, A. G., Wolff, J. O., and Phelps, S. M. (2008a). Variation in neural VlaR predicts sexual fidelity and space use among male prairie voles in seminatural settings. Proc. Natl. Acad. Sci. U.S.A. 105, 1249-1254.

Ophir,A. G., Campbell, P., Hanna, K., and Phelps, S. M. (2008b). Field tests of cisregulatory variation at the prairie vole avprla locus: association with $\mathrm{V} 1 \mathrm{aR}$ abundance but not sexual or social fidelity. Horm. Behav. 54, 694-702.

Pan, Y., Liu, Y., Young, K.A., Zhang, Z., and Wang, Z. (2009). Post-weaning social isolation alters anxiety-related behavior and neurochemical gene expression in the brain of male prairie voles. Neurosci. Lett. 454, 67-71.

Patisaul, H. B., Scordalakes, E. M., Young, L. J., and Rissman, E. F. (2003). Oxytocin, but not oxytocin receptor, is regulated by oestrogen receptor beta in the female mouse hypothalamus. J. Neuroendocrinol. 15, 787-793.

Phelps, S. M., and Young, L. J. (2003). Extraordinary diversity in vasopressin (V1a) receptor distributions among wild prairie voles (Microtus ochrogaster): patterns of variation and covariation. J. Comp. Neurol. 466, 564-576.

Pitkow, L. J., Sharer, C. A., Ren, X. Insel, T. R., Terwilliger, E. F., and Young, L. J. (2001). Facilitation of affiliation and pair-bond formation by vasopressin receptor gene transfer into the ventral forebrain of a monogamous vole. J. Neurosci. 21, 7392-7396.

Primus, R. J., Yevich, E., Baltazar, C. and Gallager, D. W. (1997). Autoradiographic localization of CRF1 and CRF2 binding sites in adult rat brain. Neuropsychopharmacology 17, 308-316.

Roberts, R. L., Miller,A. K., Taymans, S. E. and Carter, C. S. (1998). Role of social and endocrine factors in alloparental behavior of prairie voles (Microtus ochrogaster). Can. J. Zool. 76 , 1862-1868.

Roberts, R. L., Zullo, A., Gustafson, E. A., and Carter, C. S. (1996). Perinatal steroid treatments alter alloparental and affiliative behavior in prairie voles. Horm. Behav. 30, 576-582.

Ross, H. E., Freeman, S. M., Spiegel, L. L., Ren, X., Terwilliger, E. F., and Young, L. J. (2009). Variation in oxytocin receptor density in the nucleus accumbens has differential effects on affiliative behaviors in monogamous and polygamous voles. J. Neurosci. 29 , 1312-1318.
Sable, P. (2004). Attachment, ethology and adult psychotherapy. Attach. Hum. Dev. 6, 3-19.

Sanchez, M. M. (2006). The impact of early adverse care on HPA axis development: nonhuman primate models. Horm. Behav. 50, 623-631.

Sayler, A., and Salmon, M. (1969). Communal nursing in mice: influence of multiple mothers on the growth of the young. Science 164, 1309-1310.

Skodol, A. E., Siever, L. J., Livesley, W. J., Gunderson, J. G., Pfohl, B., and Widiger, T. A. (2002). The borderline diagnosis II: biology, genetics, and clinical course. Biol. Psychiatry 51, 951-963.

Stowe, J. R., Liu, Y., Curtis, J. T., Freeman, M. E., and Wang, Z. (2005). Species differences in anxiety-related responses in male prairie and meadow voles: the effects of social isolation. Physiol. Behav. 86, 369-378.

Taymans,S.E.,DeVries,A.C.,DeVries, M. B., Nelson,R.J.,Friedman, T.C., Castro, M., Detera-Wadleigh, S., Carter, C. S., and Chrousos, G. P. (1997). The hypothalamic-pituitary-adrenal axis of prairie voles (Microtus ochrogaster): evidence for target tissue glucocorticoid resistance. Gen. Comp. Endocrinol. 106, 48-61.

Wang, Z., Ferris, C. F., and De Vries, G. J. (1994). Role of septal vasopressin innervation in paternal behavior in prairie voles (Microtus ochrogaster). Proc. Natl. Acad. Sci. U.S.A. 91, 400-404.

Wang, Z. X., Liu, Y., Young, L. J., and Insel, T. R. (2000). Hypothalamic vasopressin gene expression increases in both males and females postpartum in a biparental rodent. J. Neuroendocrinol. 12, 111-120.

Wang, Z. X., and Novak, M. A. (1992). Influence of the social-environment on parental behavior and pup development of meadow voles (Microtus pennsylvanicus) and prairie voles (Microtus ochrogaster). J. Comp. Psychol. 106, 163-171.

Williams, J. R., Carter, C. S., and Insel, T. (1992). Partner preference development in female prairie voles is facilitated by mating or the central infusion of oxytocin. Ann. N.Y. Acad. Sci. 652, 487-489.

Winslow, J. T., Hastings, N., Carter, C. S., Harbaugh, C. R., and Insel, T. R. (1993). A role for central vasopressin in pair bonding in monogamous prairie voles. Nature 365, 545-548.

Yamamoto, Y., Cushing, B. S., Kramer, K. M., Epperson, P. D., Hoffman, G. E., and Carter, C. S. (2004). Neonatal manipulations of oxytocin alter expression of oxytocin and vasopressin immunoreactive cells in the paraventricular nucleus of the 
hypothalamus in a gender-specific manner. Neuroscience 125, 947-955.

Yoshida, M., Takayanagi, Y., Inoue, K., Kimura, T., Young, L. J., Onaka, T., and Nishimori, K. (2009). Evidence that oxytocin exerts anxiolytic effects via oxytocin receptor expressed in serotonergic neurons in mice. J. Neurosci. 29, 2259-2271.

Young, L. J., Huot, B., Nilsen, R., Wang, Z., and Insel, T. R. (1996). Species differences in central oxytocin receptor gene expression: comparative analysis of promoter sequences. J. Neuroendocrinol. 8, 777-783.
Young, L. J., Lopreato, G. F., Horan, K., and Crews, D. (1994). Cloning and in situ hybridization analysis of estrogen receptor, progesterone receptor, and androgen receptor expression in the brain of whiptail lizards (Cnemidophorus uniparens and, C. inornatus). J. Comp. Neurol. 347, 288-300.

Young, L. J., and Wang, Z. (2004). The neurobiology of pair bonding. Nat. Neurosci. 7, 1048-1054.

Zanarini, M. C., and Frankenburg, F. R. (1997). Pathways to the development of borderline personality disorder. J. Pers. Disord. 11, 93-104.
Zanarini, M. C., and Frankenburg, F. R (2007). The essential nature of borderline psychopathology. J Pers Disord 21, 518-535.

Conflict of Interest Statement: The authors declare that the research was conducted in the absence of any commercial or financial relationships that could be construed as a potential conflict of interest.

Received: 02 June 2009; paperpending published: 23 June 2009; accepted: 05 August 2009; published online: 27 August 2009.
Citation: Ahern TH and Young LJ (2009) The impact of early life family structure on adult social attachment, alloparental behavior, and the neuropeptide systems regulating affiliative behaviors in the monogamous prairie vole (Microtus ochrogaster). Front. Behav. Neurosci. 3:17. doi: 10.3389/neuro.08.017.2009

Copyright (c) 2009 Ahern and Young. This is an open-access article subject to an exclusive license agreement between the authors and the Frontiers Research Foundation, which permits unrestricted use, distribution, and reproduction in any medium, provided the original authors and source are credited. 